\title{
6. TEXTURAL, GEOCHEMICAL, AND ISOTOPIC VARIATIONS IN GABBROIC SHEAR ZONES FROM THE MARK AREA ${ }^{1}$
}

\author{
Susan M. Agar, ${ }^{2}$ John F. Casey, ${ }^{3}$ and Pamela D. Kempton ${ }^{4}$
}

\begin{abstract}
Gabbros recovered during Ocean Drilling Program Leg 153 from the Mid-Atlantic Ridge, south of the Kane Fracture Zone (MARK area) display remarkable textural and compositional diversity over meter to decameter scales. The textures in core samples for this study can be broadly categorized into weakly and moderately recrystallized, porphyroclastic and mylonitic. These divisions are based primarily on varying degrees of static and dynamic recrystallization in plagioclase, olivine, and clinopyroxene. Textural relations indicate that some samples were deformed under hypersolidus conditions. Whole-rock geochemical and isotopic variations have been examined to investigate the possible correlations between strain localization, melt migration, and hydrothermal alteration. Preliminary results show that there are no systematic variations of strontium-isotope ratios with textural variations or with depth. This may indicate only limited seawater-rock interaction. Alternatively, if deformation occurred at mid-to-lower crustal depths, the seawater composition may have been buffered by the overlying rock column. Neodymium-isotope ratios are consistent with primary magmatic values. Whole-rock lead isotopes have significantly more radiogenic lead-isotope ratios than primary magmatic values, and may therefore be more sensitive to alteration. Mineral chemistry indicates highly heterogeneous plagioclase compositions ( $\mathrm{mm}$ to decameter scales) generated during dynamic recrystallization and post-kinematic alteration. Deformed samples tend to have a lower anorthite content than undeformed samples, but there are several inconsistencies. Downhole variations in incompatible elements indicate that concentrations of latestage melt fractions correspond to intervals $0-30 \mathrm{mbsf}$ at each drill site and $60-70 \mathrm{mbsf}$ at Holes $921 \mathrm{E}$ and $923 \mathrm{~A}$. High-temperature shear-zone fabrics (amphibolite to granulite facies) are concentrated in these intervals, but there are no systematic geochemical variations with the intensity of deformation within these intervals. Strain localization may have been promoted by zones of high residual melt porosity. If late-stage melt migration was focused by shearing, consequent local temperature elevations may have accelerated recovery mechanisms and promoted dislocation creep. A higher bulk plagioclase (and in some cases quartz) content, transient low effective stresses, and melt assisted diffusion creep may also have weakened these zones.
\end{abstract}

\section{INTRODUCTION}

Seafloor spreading at slow-spreading centers is accommodated by a combination of multiple magmatic intrusions and mechanical extension by faulting. It has been proposed that extreme end members of this process are either magma-dominated, during periods of high magma supply, or "tectonically" dominated, when there is little or no magma (e.g., Karson et al., 1987; Karson and Winters, 1992). There is clearly a broad spectrum between these two end members that must be prevalent in many parts of slow-spreading systems where magmatism and fault displacements contribute in varying degrees to crustal divergence. The detailed physical and chemical processes involved in the interactions between magmatism and faulting are critical for understanding the variations in deformation environments (e.g., temperature and fluid pressure), magma migration paths, and chemical differentiation processes (e.g., RIDGE Workshop, 1995). Post-crystallization chemical transformations are further enhanced by hydrothermal circulation. Aqueous fluid migration in shear zones will also promote changes in the thermal, fluid pressure, and fluid chemistry conditions during deformation. The magmatic and alteration histories associated with shear-zone evolution are therefore key parameters in the rheological evolution of the oceanic lithosphere.

Investigations of chemical transformations in shear zones have been mainly restricted to the role of aqueous fluids, primarily in continental settings (e.g., Beach, 1976; McCaig, 1984; Kerrich, 1986).

'Karson, J.A., Cannat, M., Miller, D.J., and Elthon, D. (Eds.), 1997. Proc. ODP, Sci. Results, 153: College Station, TX (Ocean Drilling Program).

${ }^{2}$ Geological Sciences Department, Northwestern University, 1847 Sheridan Rd., Evanston, IL 60208, U.S.A. agar@earth.nwu.edu

${ }^{3}$ Geosciences Dept., University of Houston, Houston, TX 77204-5503, U.S.A.

${ }^{4}$ NERC Isotope Geosciences Laboratory, Keyworth, NG12 5GG, United Kingdom.
The interactions between hydrothermal alteration and brittle failure have been studied using samples from in situ ocean crust (Agar, 1990,1991 ) or from inferred oceanic fault zones in ophiolites (Alexander et al., 1992). Deformation of partially molten material (e.g., van der Molen and Paterson, 1979; Paquet and Francois, 1980; Cooper and Kohlstedt, 1986; Dell'Angelo and Tullis, 1988; Means and Park, 1994; Rutter and Neumann, 1995) and the interactions of magma migration and strain localization (e.g., Bowen, 1920; Hollister and Crawford, 1986; Hibbard, 1987; Antonellini and Cambray, 1992; Cambray et al., 1995) have received only limited attention. Ocean Drilling Program (ODP) Leg 118 (Southwest Indian Ridge) recovered sections of variably deformed gabbroic rocks that reveal a close spatial association between late-stage magma fractions and shear zones (Robinson, Von Herzen, et al., 1989). A preliminary model, in which deformation leads to the channeling of intercumulus melts out of the olivine gabbro cumulates into shear zones, was proposed to explain the textural relations in the Leg 118 cores (Bloomer et al., 1991).

A primary objective of this pilot investigation was to evaluate the geochemical and isotopic evidence for enhanced melt mobility and seawater-rock interaction in deforming zones. We have also compared the microstructural, isotopic, and geochemical signatures of samples to determine whether geochemical and isotopic variations can be related to variations in the deformation state.

\section{TECTONIC SETTING OF SITES 921, 922, AND 923}

Sites 921,922 , and 923 are located $10 \mathrm{~km}$ south of the Kane Transform on the western wall of the median valley of the MidAtlantic Ridge (MARK). This wall forms the edge of the inner corner 
high (Fig. 1). Sites 921-923 penetrated the seafloor at depths ranging from 2500 to 2650 meters below seafloor (mbsf), and from 500 to $600 \mathrm{~m}$ below the peak of the inner corner high, close to the location of previous ODP drilling at Site 669 (Detrick, Honnorez, Bryan, Juteau, et al., 1988), which penetrated a basaltic carapace at $1980 \mathrm{~m}$ water depth (Fig. 1). Magnetic anomalies indicate asymmetric crustal spreading over the last 2 million years and spreading rates of 14.1 $\mathrm{mm} / \mathrm{yr}$ to the west and $11.3 \mathrm{~mm} / \mathrm{yr}$ to the east (Schulz et al., 1988). All three sites are located in approximately 1-m.y.-old crust. The exposure of gabbroic and ultramafic rocks in this region (e.g., Karson and Dick, 1983; Mével et al., 1991) has been attributed to exhumation by a major low-angle normal detachment fault (Dick et al., 1981; Karson and Dick, 1983; Karson et al., 1987) generated during a period of reduced magma supply. In this model, Sites 921 and 922 would be located in the footwall of the detachment fault, and the gabbroic rocks would represent middle-to-lower crustal rocks.

Core samples recovered from Sites 921, 922, and 923 comprise gabbro and olivine gabbro, with smaller proportions of troctolite and $\mathrm{Fe}-\mathrm{Ti}$ oxide gabbros. These rocks are cut by veins of leucogabbro, quartz diorite, and trondhjemite, generally thought to represent products of more extensive melt fractionation (Cannat, Karson, Miller, et al., 1995). Overall, there is only limited alteration (represented by amphibolite, greenschist, and zeolite mineral assemblages), but on $\mathrm{mm}$ to $\mathrm{cm}$ scales, the extent of alteration is highly variable.

The style and intensity of deformation vary widely (Pl. 1). Some core samples preserve a weak mineral shape-preferred orientation (usually defined by clinopyroxene) with a dynamically recrystallized plagioclase matrix. Other core samples contain discrete, strongly foliated, and variably lineated shear zones in which all mineral phases are penetratively mylonitized. Both crystal-plastic fabrics and magmatic foliations have variable dips that range from subhorizontal to subvertical and exhibit curviplanar traces in some places. Melt migration during deformation is indicated by deformed and undeformed gabbroic and trondhjemitic veins that cut crystal-plastic shear zones.

A high proportion of the core samples displays textures indicative of high-temperature deformation involving dynamic recrystallization of plagioclase, olivine, clinopyroxene, and, in some instances, $\mathrm{Fe}-\mathrm{Ti}$ oxides (see Agar and Lloyd, this volume). The deformation temperature conditions are broadly constrained by synkinematic and postkinematic brown hornblende. This provides a lower limit for the recrystallization of clinopyroxene between $700^{\circ} \mathrm{C}$ and $900^{\circ} \mathrm{C}$ (Spear, 1981; Cannat, Karson, Miller, et al., 1995). Crystal-plastic deformation fabrics are postdated by hydrothermal veins containing actinolite, tremolite, talc, and chlorite, constraining subsequent lowermost recrystallization temperatures for plagioclase to $300^{\circ}-450^{\circ} \mathrm{C}$ (Liou et al., 1974; Cannat, Karson, Miller, et al., 1995). The pressure conditions are unconstrained except for maximum depth limits imposed by seismic estimates of crustal thickness in the MARK area $(4 \mathrm{~km}$ in the median valley to the east of Sites 921-923, and $6 \mathrm{~km}$ thick in the ridge segment to the south; Purdy and Detrick, 1986).

Cataclastic zones occur mainly at the top of Holes 921A, 921B, 921C, 921E, and 923A, and also overprint crystal-plastic shear zones in the lower parts (below $50 \mathrm{mbsf}$ ) in Hole 923A. Synkinematic greenschist mineral assemblages (actinolite, actinolite and chlorite) indicate maximum deformation temperatures during cataclasis of about $450^{\circ} \mathrm{C}$. Zeolites are rare, suggesting that fluid circulation did not occur below $300^{\circ}$ to $400^{\circ} \mathrm{C}$ (Cannat, Karson, Miller, et al., 1995).

\section{METHODS}

Three approaches were used for this study. Microstructures (optical and electron microscopy) provided a basis for interpreting the deformation mechanisms, identifying textural characteristics indicative of synkinematic melt migration, and evaluating deformation histories. Whole-rock geochemistry (X-ray fluorescence $[\mathrm{XRF}]$ and inductively coupled plasma [ICP]) and mineral analyses (electron microprobe) were used to investigate elemental variations within individual shear

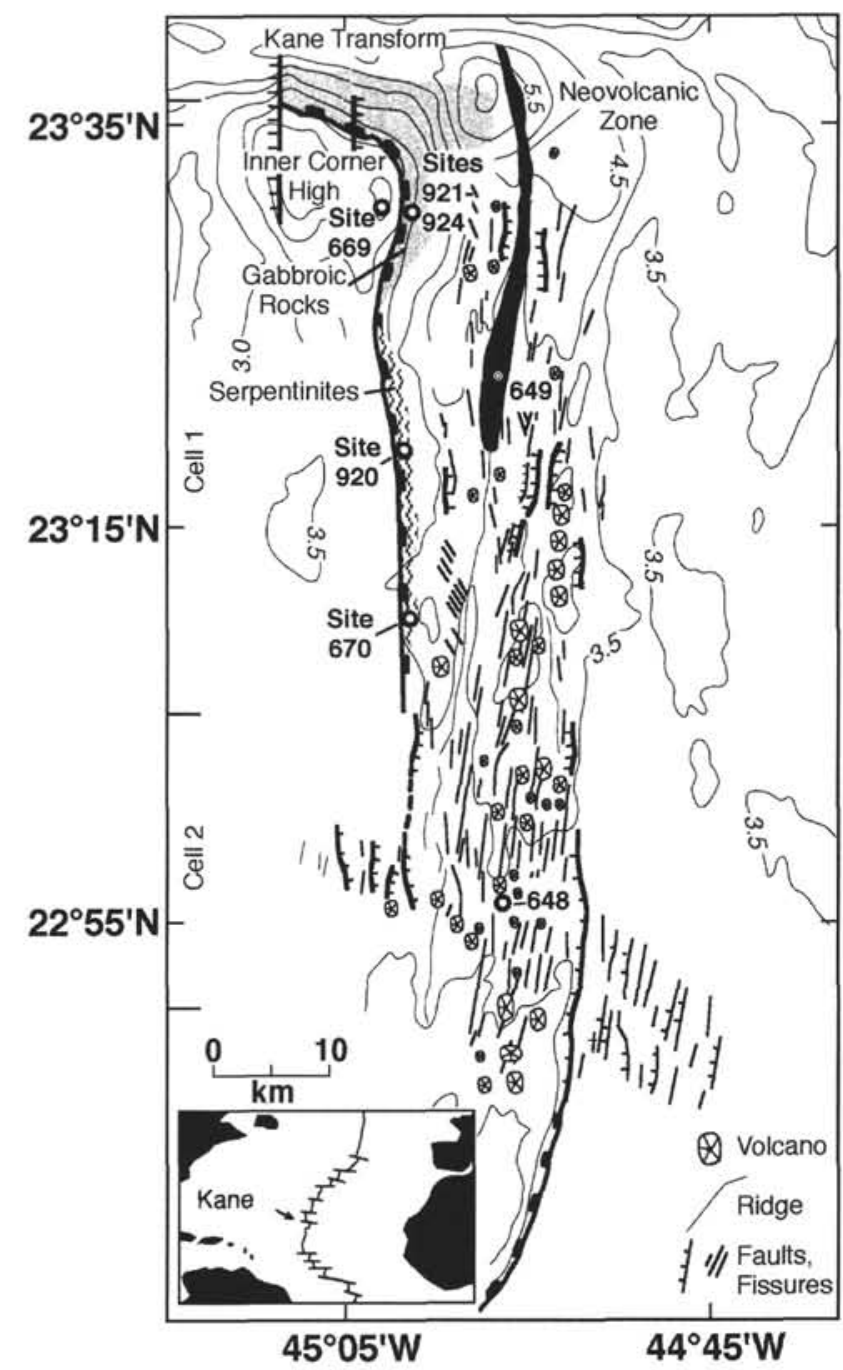

Figure 1. Location of Sites 921,922 , and 923 on the edge of the inner-corner high of the MARK area (modified from Shipboard Scientific Party,.1995b). Other Leg 153 drill sites and previous ODP/Deep Sea Drilling Project (DSDP) sites are also indicated. Zones of gabbroic rock (stipple) and serpentinite exposures (squiggles) and the neovolcanic zone (black) are shown. Bathymetric depth contours in $\mathrm{km}$.

zones and among different shear zones. Isotopic $(\mathrm{Sr}, \mathrm{Nd}, \mathrm{Pb})$ analyses were used to explore the extent of fluid (melt or seawater) influx during deformation.

Microstructures were investigated using polished thin sections ( $25 \mu \mathrm{m}$ thick) and samples mounted and polished in resin blocks. Grain-size estimates were averaged from a maximum of 200 measurements on each thin section using the linear intercept method (Underwood, 1970). Grain-size data have not been stereologically corrected and do not account for limits imposed by the thin-section thickness. Plagioclase petrofabric analysis was used to compare the preferred crystallographic orientation of different shear-zone textures. Petrofabrics were measured on a Zeiss universal stage following the procedures outlined by Wenk et al. (1986). A JEOL 733 Superprobe was used for backscatter imaging and wavelength-dispersive analyses of plagioclase using the Bence-Albee data-reduction routines.

Isotope analyses were conducted using the techniques outlined by Kempton and Hunter (this volume), with the exception that this study used unleached whole-rock powders, whereas Kempton and Hunter analyzed mineral separates leached in 6-M HCl. Whole-rock major-, trace-, and rare-earth element analyses were conducted at the Univer- 
sity of Houston using a Thermo-Jarrell Ash Sequential ICP-AES. Methods are reported in Casey (this volume).

\section{SAMPLE SELECTION}

The ODP sampling guidelines limit the sample size and the amount of sampling (25\%) from any core interval for all investigators. Under these conditions, it was not possible to acquire sufficient material from a single core interval for combined geochemical, isotopic, and microstructural studies. Therefore, samples with similar compositions and deformation fabrics were selected from adjacent intervals or from the next permissible sample location, depending on other shipboard scientists' requests. Thirty-seven samples were acquired to provide adequate material from 18 intervals from Holes 921B, 921D, 921E, 922A, 922B, and 923A (Fig. 2; Table 1). These intervals included a representative suite of deformation textures in gabbroic shear zones ranging from weakly recrystallized to mylonitic textures in a wide range of modal compositions (Pl. 1). Samples in which deformation was clearly postdated by a moderate-to strong hydrothermal overprint were generally avoided. The 30 samples studied here were less than $25 \%$ altered. Seven more altered $(40 \%-90 \%)$ samples were used for microstructural and comparative geochemical studies, but were not included in the isotope sample suite.

The distribution of structures related to crystal-plastic deformation for the sampled holes is shown in Figure 3 (see also Cannat, Karson, Miller, et al., 1995). During shipboard core description, a qualitative "intensity" was assigned to deformation fabrics $(0=$ none or very weak deformation, to $4=$ strongest deformation). The basis for assigning an intensity value is described in Shipboard Scientific Party (1995a). Because of the generally low recovery at Sites 921-923 (ranging from $11 \%$ to $75 \%$ ) estimates of the thickness and spacing of core-scale shear zones may not be representative of the entire drilled section. Shear zones range from isolated structures $<1 \mathrm{~cm}$ wide to greater than $5 \mathrm{~m}$ in thickness. The maximum spacing between shear zones is constrained only by the maximum length intervals between recovered sections containing deformation fabrics (about $10 \mathrm{~m}$ ). In Hole $921 \mathrm{~B}$ ( $44.10 \mathrm{~m}$ penetration; $29 \%$ recovery), strong crystal-plastic fabrics have been overprinted by cataclasis in the uppermost 0.5 $\mathrm{m}$. Crystal-plastic deformation also occurs between 14.71 and 15.64 mbsf, and between 15.84 and 16.85 mbsf. A third shear zone occurs at $25.41 \mathrm{mbsf}$. In Hole 921D (48.6 m penetration; $12 \%$ recovery), there are no strong crystal-plastic fabrics, but narrow (5- to $10-\mathrm{cm}$, isolated shear zones occur at 10.08, 29.44-29.66, 39.2, and $40.45 \mathrm{mb}-$ sf. The first $25 \mathrm{~cm}$ at the top of Hole $921 \mathrm{E}$ ( $82.6 \mathrm{~m}$ penetration; $21 \%$ recovery) preserves a strong crystal-plastic fabric. Below this are shear zones at 11.66-11.96 mbsf, 19.8-20.66 mbsf, 39.6-40.64 mbsf, 49.82-51.38 mbsf, $61.95 \mathrm{mbsf}$, and $69.29-69.87 \mathrm{mbsf}$. The strongest deformation (based on qualitative core evaluations) occurs at 11.66 and 39.6 mbsf. In Hole 922A (14.6 m penetration; 63\% recovery), strong crystal-plastic fabrics occur between 0.68 and $1.21,10.32$ and $11.15,12.5$ and $14.38 \mathrm{mbsf}$ with discrete shear zones at 7.52, 8.02, and 9.07 mbsf. In Hole $922 \mathrm{~B}$ ( $37.4 \mathrm{~m}$ penetration; $31 \%$ recovery) the interval from 0.66 to 1.61 mbsf contains several discrete shear zones and a moderately intense crystal-plastic fabric. The deformation intensifies again at 15.10 to $17.34 \mathrm{mbsf}$ and $26.57 \mathrm{mbsf}$. Between these latter two intervals there are several minor shear zones spaced at less than $5 \mathrm{~cm}$ to $0.5 \mathrm{~m}$. Hole $923 \mathrm{~A}$ ( $70 \mathrm{~m}$ penetration; $74.7 \%$ ) contains the most strongly deformed gabbro section of all the gabbro sites drilled during Leg 153. Most of the strong crystal-plastic deformation occurs below $16.44 \mathrm{mbsf}$. Between this level and $69.11 \mathrm{mbsf}$, numerous shear zones are concentrated in the intervals 16.44-21.16 mbsf, 39.19-54.21 mbsf, and 60.30-69.11 mbsf.

During shipboard core description it was noted that penetrative crystal-plastic fabrics in Holes 921B, 921C, and 921E tended to be concentrated in pyroxene-rich or olivine-poor gabbro (including ferrogabbro and gabbro norite). For the restricted sample set used in this study, no clear correlation between the modal composition and the in-

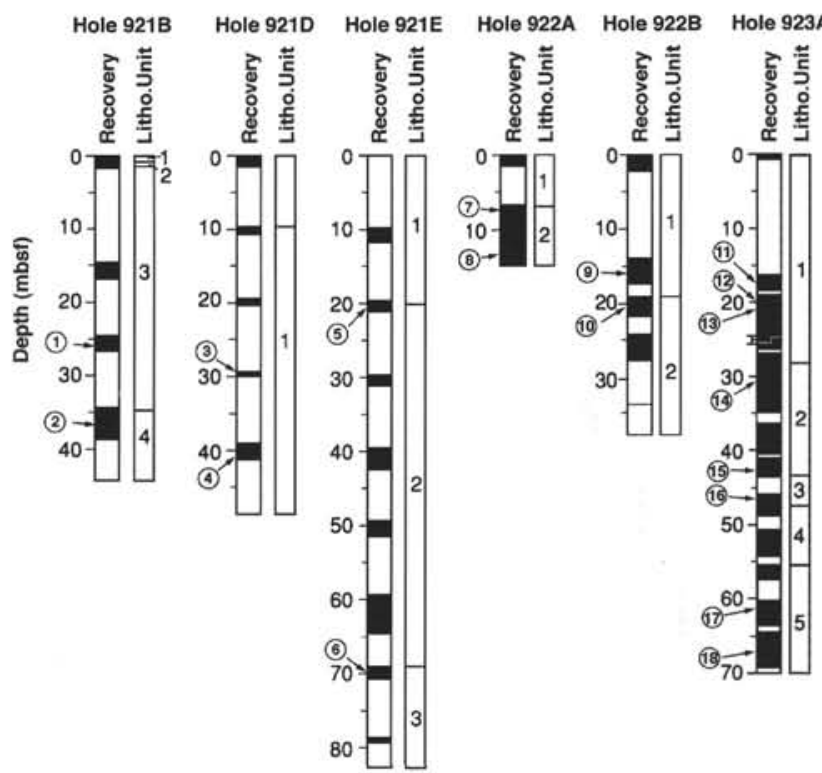

Figure 2. Approximate depth locations of sample intervals (circled numbers) used in this study. Black intervals show the core recovery (Rec.). Lithologic units defined for each borehole are numbered in the adjacent column (Unit). See Cannat, Karson, Miller, et al. (1995) for full descriptions of lithologies. Note that the same numbers do not correspond to the same lithologies in each hole. The following lithologic unit names were assigned during shipboard description (Cannat, Karson, Miller, et al., 1995): Hole 921B: 1 = cataclastic metagabbro, 2 = aphyric to sparsely phyric diabase, $3=$ lineated gabbro, $4=$ poikilitic olivine gabbro. Hole 921D: sediment and rubble overlie Unit $1.1=$ mixed gabbro and olivine gabbro. Hole $921 \mathrm{E}: 1$ = very coarse grained to pegmatitic gabbro, 2 = heterogeneous poikilitic olivine gabbro, $3=$ varitextured gabbro and olivine gabbro. Hole 922A: 1 = metatroctolite, 2 = troctolite and olivine gabbro. Hole 922B: 1 = troctolite and olivine gabbro, 2 = poikilitic olivine gabbro. Hole 923A: 1 = variably deformed gabbro and olivine gabbro, 2 = interlayered troctolite and olivine gabbro, $3=$ poikilitic olivine gabbro and troctolite, $4=$ varitextured gabbro and olivine gabbro, $5=$ troctolite and poikilitic olivine gabbro.

tensity of the deformation is apparent, although several of the undeformed samples have a high olivine content (Fig. 4). A rigorous investigation of the correlation of bulk composition with the location and intensity of deformation is beyond the scope of this study. We emphasize that correlations between qualitative estimates of finite strain and bulk composition are of limited value unless they carefully document the spatial relationships of strain localization to compositional and textural variations. Furthermore, modal composition estimates for our samples vary by more than $20 \%$ in some cases for the same sample, simply depending on the scale of observation (e.g., thin section vs. core; Fig. 4). Thus, constraining the influence of composition and primary texture on strain localization requires integrated observations from a wide range of scales.

For this study, we have categorized samples by their microstructural characteristics into four broad categories (Tables 1,2). In the following section we outline the distinguishing features for each texture and interpret the conditions and mechanisms of deformation. The geochemical and isotopic signatures of the samples and their relation to textural variations are then discussed.

\section{MICROSTRUCTURES}

Parameters used to evaluate the deformation textures for this study include the development of microstructures associated with crystal-plasticity (subgrains, neoblasts, porphyroclasts, sutured grain boundaries, deformation twins, kink bands), the percentage of recrys- 
Table 1. Core sample depths and lithologies with the textural categories assigned in this study.

\begin{tabular}{|c|c|c|c|c|c|c|c|}
\hline $\begin{array}{l}\text { Study } \\
\text { interval }\end{array}$ & Hole, core, section, interval $(\mathrm{cm})$ & $\begin{array}{l}\text { Depth to center of } \\
\text { interval (mbsf) }\end{array}$ & Geochemistry & Isotopes & Microstructure & Lithology & Texture \\
\hline 1 & $921 \mathrm{~B}-3 \mathrm{R}-2,43-46$ & 26.8 & $\mathrm{x}$ & & $x$ & Gabbro & $\mathbf{P}$ \\
\hline 2 & $4 \mathrm{R}-2,71-76$ & 36.33 & $\mathrm{x}$ & $\mathrm{x}$ & $\mathrm{x}$ & Poikilitic olivine gabbro & $\mathrm{P}$ \\
\hline 3 & $921 \mathrm{D}-4 \mathrm{R}-1,36-43$ & 29.64 & $\hat{x}$ & $\mathrm{x}$ & & Gabbro/oxide gabbro & $\mathrm{P}$ \\
\hline 3 & $4 \mathrm{R}-1,59-63$ & 29.92 & $\mathrm{x}$ & & & $\begin{array}{l}\text { Gabbro/oxide gabbro in layered contact with medium- } \\
\text { grained oxide gabbro }\end{array}$ & $\mathrm{P}$ \\
\hline 4 & $5 R-2,68-73$ & 41.04 & $\mathrm{x}$ & & $x$ & Isotropic olivine gabbro & WR \\
\hline Misc & $921 \mathrm{E}-3 \mathrm{R}-1,41-44$ & 20.21 & & & $\hat{x}$ & Olivine gabbro cut by oxide gabbro & M \\
\hline 5 & $3 \mathrm{R}-1,66-72$ & 20.46 & $\mathrm{x}$ & $\mathrm{x}$ & $\mathrm{x}$ & Olivine gabbro with cumulus texture & WR \\
\hline 6 & $8 \mathrm{R}-1,78-80$ & 69.86 & $x$ & & $\mathrm{x}$ & Gabbro/oxide gabbro with felsic veinlets & $\mathrm{P} / \mathrm{M}$ \\
\hline 6 & $8 \mathrm{R}-1,91-95$ & 69.91 & $\mathrm{x}$ & & $\mathrm{x}$ & Oxide gabbro with felsic veinlets & $\mathrm{P}$ \\
\hline 6 & $8 \mathrm{R}-1,118-125$ & 70.18 & $\mathrm{x}$ & $\mathrm{x}$ & $\mathrm{x}$ & Clinopyroxene-bearing troctolite with felsic dikelets & $\mathrm{P}$ \\
\hline 7 & $922 \mathrm{~A}-2 \mathrm{R}-1,83-87$ & 7.43 & $\mathrm{x}$ & & $\mathrm{x}$ & Troctolite & $\mathrm{P} / \mathrm{M}$ \\
\hline 8 & $2 \mathrm{R}-5,69-76$ & 13.29 & & & $\hat{x}$ & Olivine gabbro with oxide gabbronorite & $\mathrm{P}$ \\
\hline 8 & $2 \mathrm{R}-5,85-90$ & 13.45 & $x$ & & & Olivine gabbro with oxide gabbronorite & $\mathrm{P}$ \\
\hline 9 & $922 \mathrm{~B}-2 \mathrm{R}-2,0-8$ & 15.49 & $\mathrm{x}$ & & & Oxide olivine gabbro & $\mathrm{P}$ \\
\hline 9 & $2 \mathrm{R}-2,73-77$ & 16.22 & $\hat{\mathbf{x}}$ & & $\mathrm{x}$ & Olivine gabbronorite & $\mathrm{P}$ \\
\hline 10 & $3 \mathrm{R}-2,14-21$ & 20.34 & $\mathrm{x}$ & $\mathrm{x}$ & & Olivine gabbro & WR \\
\hline Misc & $4 \mathrm{R}-1,67-74$ & 24.67 & & & $\mathrm{x}$ & Meta-olivine gabbro & WR \\
\hline 11 & $923 \mathrm{~A}-2 \mathrm{R}-1,83-87$ & 17.37 & & & $\mathrm{x}$ & Gneissic gabbro & $\mathrm{P}$ \\
\hline 11 & $2 \mathrm{R}-1,108-113$ & 17.48 & $x$ & $\mathrm{x}$ & $\hat{x}$ & Gneissic gabbro & $\mathrm{P}$ \\
\hline 12 & $3 \mathrm{R}-1,10-13$ & 19.30 & $\mathrm{x}$ & & & Gneissic oxide gabbro ( $5 \%-10 \%$ oxide minerals) & $\mathrm{P}$ \\
\hline 12 & $3 \mathrm{R}-1,100-105$ & 20.20 & & & $\mathrm{x}$ & Gneissic olivine gabbro & MR \\
\hline 12 & $3 \mathrm{R}-1,126-132$ & 20.49 & $\mathrm{x}$ & $\mathrm{x}$ & & Gneissic olivine gabbro & $\mathrm{P}$ \\
\hline 13 & $3 R-2,47-51$ & 21.16 & & & $\mathrm{x}$ & Gneissic olivine gabbro & $\mathrm{P}$ \\
\hline 13 & $4 \mathrm{R}-1,3-10$ & 21.23 & $x$ & & & Oxide olivine gabbro (oxides $5 \%-10 \%$ ) & $\mathrm{P}$ \\
\hline 14 & $8 \mathrm{R}-1,48-52$ & 29.48 & $\mathrm{x}$ & & $\mathrm{x}$ & Olivine gabbro/troctolite & WR \\
\hline 14 & $8 \mathrm{R}-1,111-115$ & 30.10 & $\hat{x}$ & $\mathrm{x}$ & $\mathrm{x}$ & Olivine gabbro/troctolite & WR \\
\hline 14 & $8 R 2,13-19$ & 30.60 & & & $\mathrm{x}$ & Gabbro & WR \\
\hline 14 & $8 \mathrm{R}-2,81-88$ & 31.27 & & & $\mathrm{x}$ & Gabbro & WR \\
\hline 15 & $11 \mathrm{R}-2,18-23$ & 42.74 & & & $\mathrm{x}$ & Gabbro cut by felsic veins & MR \\
\hline 15 & $11 \mathrm{R}-2,30-34$ & 42.86 & & & $\mathrm{x}$ & Gabbro & MR \\
\hline 15 & $11 R-2,40-48$ & 42.96 & & $\mathrm{x}$ & $\hat{x}$ & Gabbro & MR \\
\hline 16 & $12 \mathrm{R}-1,66-69$ & 46.66 & & & $x$ & Poikilitic olivine gabbro & WR \\
\hline 16 & $12 \mathrm{R}-1,69-74$ & 46.69 & $\mathrm{x}$ & $\mathrm{x}$ & $\mathrm{x}$ & Poikilitic olivine gabbro & WR \\
\hline 17 & $15 \mathrm{R}-1,109-113$ & 61.39 & & & $\mathrm{x}$ & Metagabbro & $\mathrm{P}$ \\
\hline 17 & $15 \mathrm{R}-1,117-122$ & 61.47 & & & $\mathrm{x}$ & Metagabbro & $\mathrm{P} / \mathrm{M}$ \\
\hline 17 & $15 \mathrm{R}-2,0-6$ & 61.53 & $\mathrm{x}$ & & & Olivine gabbro & $\mathrm{P}$ \\
\hline 18 & $16 \mathrm{R}-3,118-124$ & 68.31 & $\hat{x}$ & & $\mathrm{x}$ & Microgabbro/gabbro & M \\
\hline
\end{tabular}

Notes: Misc $=$ additional microstructural samples. $\mathrm{WR}=$ weakly recrystallized, $\mathrm{MR}=$ moderately recrystallized, $\mathrm{P}=$ porphyroclastic, $\mathrm{M}=$ mylonitic .

tallization and subgrain and recrystallized grain size, the degree of shape-preferred orientation and crystallographic preferred orientation, and the interconnectivity of deformed phases (Table 2). The textural types outlined here represent only those samples used in this study, and do not represent the entire spectrum of deformation textures within the Leg 153 gabbro cores. Because of the variable protolith textures and compositions, and the different roles of hypersolidus and solid-state processes during deformation, similar textures in different samples do not necessarily imply that samples followed the same deformation paths.

\section{Weakly Recrystallized Texture}

In the least-deformed samples, relict igneous textures are evident (Pl. 2, Figs. 1, 5). Several samples categorized here as "weakly recrystallized" were originally recorded as "undeformed" during shipboard description. No foliation or lineation is apparent in thin section or in core sample. Crystallographic preferred orientation is generally not evident with the gypsum plate inserted, except for a few small (2$3 \mathrm{~mm}$ ) domains of weak crystallographic preferred orientation in plagioclase and olivine (but not shape-preferred orientation). There is a maximum of about $15 \%$ recrystallization of plagioclase and up to $10 \%$ of olivine is recrystallized. The subhedral morphologies and straight exsolution lamellae in clinopyroxene grains indicate that they are undeformed.

Relict plagioclase grains commonly display a very weak undulose extinction, and contain thin, tapering úeformation twins, primarily on albite but also pericline laws (Pl. 2, Fig.2). The twins are deformed by gentle bends, kink bands (up to $1 \mathrm{~mm}$ wide), and microfaults ( $\mathrm{Pl}$. 2, Fig. 4). Most of the kink bands and microfaults are oriented at a high angle to albite twins aligned close to (001), as commonly observed in other studies of plagioclase deformation (e.g., Oleson 1987; Olsen and Kohlstedt, 1985). Plagioclase neoblasts are generally equant with gently curved boundaries and commonly have $120^{\circ}$ triple junctions. There are some small lobate protrusion on the boundaries of some neoblasts and relict plagioclase grains, but they are not strongly serrated. Plagioclase neoblast grain size is relatively large ( $170 \mu \mathrm{m}$; Table 2$)$ and the distribution of neoblasts appears to be independent of the location of relict plagioclase grain boundaries. More than $50 \%$ of the neoblasts display twinning (estimates depending partly on the orientation of the thin section relative to the shear plane; Kruhl, 1987; Zhao and Zhao, 1994), but very few $(<5 \%)$ have undulose extinction. In contrast to the relict plagioclase grains, twins in most of the plagioclase neoblasts are generally straight and of even thickness. Subgrains are comparatively rare (probably $<2 \%$ of recrystallized material) but can be identified where they rotate deformation twins by $2^{\circ}-15^{\circ}$ within the outer margins of relict plagioclase grains (Pl. 2, Fig. 1). The subgrain size $(125 \mu \mathrm{m})$ is slightly smaller than that of neoblasts.

Olivine neoblasts have gently curved to slightly bulged grain boundaries. Their junctions with other neoblasts are commonly defined by $120^{\circ}$ triple points. Neoblast grain size is similar to that of plagioclase (190 $\mu \mathrm{m}$; Table 2). (Pl. 2, Fig. 1). Kink bands parallel to (001) are present in some olivine porphyroclasts.

\section{Moderately Recrystallized Texture}

Relict igneous textures are preserved in some clinopyroxene oikocrysts, but most grain boundaries are serrated and are surrounded by recrystallized phases. Subplanar zones of the plagioclase matrix define a weak foliation. Domains of moderate crystallographic preferred orientation in plagioclase are indicated by the weak alignment of plagioclase neoblast albite twins and homogeneous interference colors with a gypsum plate. No crystal shape-preferred orientation is evident. From $15 \%$ to $50 \%$ of the plagioclase is recrystallized. Olivine is up to $20 \%$ recrystallized, whereas clinopyroxene is less than $5 \%$ recrystallized.

Relict plagioclase grains display undulatory extinction, and also contain curved, tapering albite and pericline twins. Microfaults and kink bands at high angles to the albite twins are present. Kink bands 

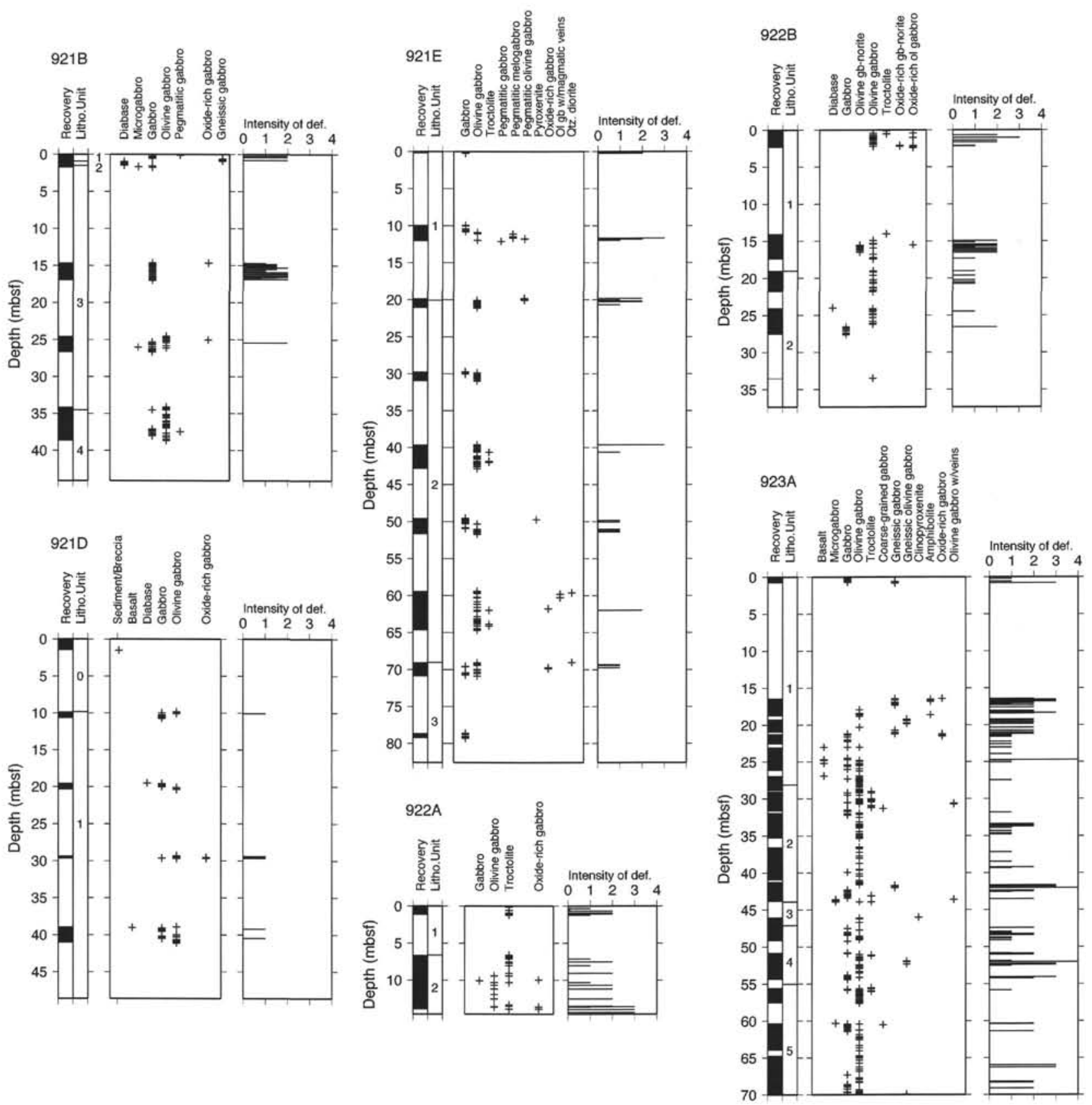

Figure 3. Distribution and intensity of crystal-plastic fabrics in holes sampled for this study. Plots shown here are constructed from data available on CD-ROM (Cannat, Karson, Miller, et al., 1995). Left-hand columns show zones of core recovery (black) and lithologic units as described in Figure 2. The center columns indicate lithologies based on core piece descriptions.

tend to be narrower (less than $0.5 \mathrm{~mm}$ ) and more numerous than those of the weakly recrystallized texture, but have the same orientation. Plagioclase neoblast grain sizes are still relatively large, and show a similar wide range to that of the weakly recrystallized texture $(140$ $\mu \mathrm{m}$; Table 2). Neoblast grain boundaries tend to be more irregular than those in the weakly recrystallized texture (Pl. 2, Fig. 3). More than $50 \%$ of the neoblasts are twinned, but in contrast to the weakly recrystallized texture, the neoblast twins tend to be more tapered and discontinuous. Subgrains $(<10 \%$ of recrystallized material, $125 \mu \mathrm{m})$ develop in zones $200-300 \mu \mathrm{m}$ thick along the margins of relict plagioclase grains, but are rare in neoblasts.

Recrystallized olivine occurs as aggregates of 10 to 20 grains generally located towards the margins of olivine porphyroclasts. An igneous morphology is still at least partly evident in most olivine grains. The average grain size in olivine for samples in this study is similar to that of the weakly recrystallized texture $(210 \mu \mathrm{m})$. A few domains of recrystallized olivine show crystallographic preferred orientation (gypsum plate). Wherever kink bands are evident, it is generally possible to identify subgrains that rotate kink bands by up to $10^{\circ}$. The subgrains tend to have a slightly longer dimension on the margins closest to the original kink-band orientation, but are otherwise of similar size to the olivine neoblasts (Table 2).

Clinopyroxene remains largely undeformed except for narrow (100-300 $\mu \mathrm{m}$ wide) recrystallized margins in some grains (about $5 \%$ ). Clinopyroxene neoblasts generally have rounded to weakly serrated margins, and a weak undulose extinction is present in the relict grains. The recrystallized grain size $(60 \mu \mathrm{m})$ is noticeably smaller than that of either olivine or plagioclase.

In both the weakly and moderately recrystallized textures, clinopyroxene oikocrysts are generally not recrystallized, but individual oikocrysts are commonly separated into two or more pieces (Pl. 2, Fig. 5). These separations have localized along the margins of plagio- 

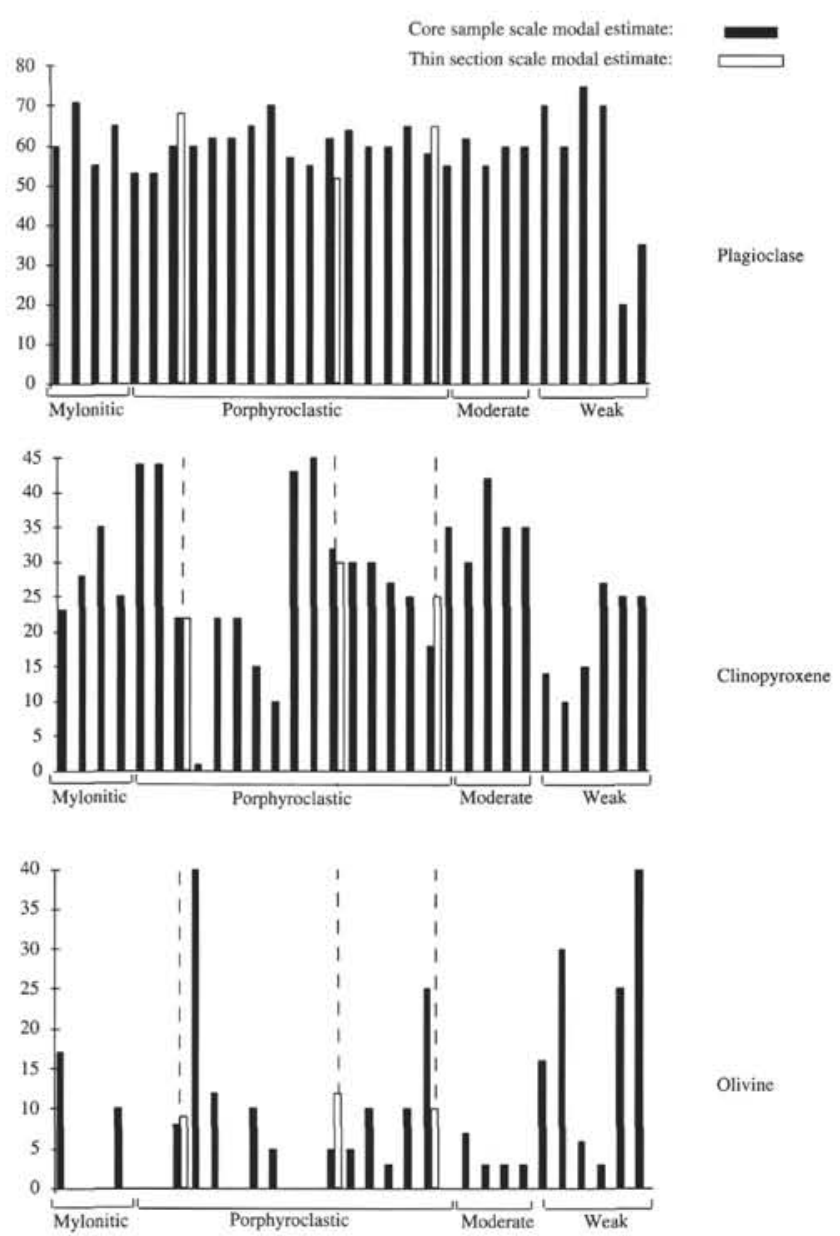

Figure 4. Modal composition vs. textural type for all samples in this study based on core sample estimates. Open columns shown thin-section estimates for three of the same samples for comparison. Adjacent core samples with identical modal compositions are not repeated in this plot.

clase inclusions that are partly or completely recrystallized within the clinopyroxene grain. In some cases, microshear zones ( 1 to 5 neoblasts wide) extend from the tips of inclusions to pyroxene grain boundaries. If the spectrum of textural relations observed is representative of a continuum of deformation, then it indicates that originally isolated inclusions have become interconnected with the surrounding plagioclase matrix during deformation. We suggest that recrystallizing plagioclase inclusions have flowed along microcracks (or intragranular shear zones mentioned above) localized at inclusion tips. Thus, an originally intact clinopyroxene grain is divided into two or more parts that can move independently within the interconnected plagioclase matrix (Pl. 2, Fig. 5). The relatively planar margins of the divided clinopyroxene grains give core samples a brecciated appearance. It would be difficult to distinguish this texture from that generated by the forceful injection (hydrofracturing) of a late-stage melt that has been subsequently recrystallized (see below).

\section{Porphyroclastic Texture}

The porphyroclastic texture is characterized by moderately to strongly aligned porphyroclasts of plagioclase (aspect ratios generally vary from 1:2 to 1:5 and peak values exceed 1:10 in some cases) surrounded by mantles of dynamically recrystallized plagioclase (PI. 3 , Figs. 2,3 ). Relict igneous textures are only preserved in a few pyroxene oikocrysts $(<10 \%)$. The foliation is defined by the preferred dimensional orientation of porphyroclasts and the crystallographic and shape-preferred orientations of recrystallized plagioclase and oli- vine. Between $50 \%$ and $70 \%$ of plagioclase is recrystallized. Up to $50 \%$ recrystallization occurs in olivine, but only $15 \%-30 \%$ recrystallization occurs in clinopyroxene (Pl. 3, Fig. 1).

Plagioclase porphyroclasts contain numerous deformation twins that are strongly curved and or kinked. The porphyroclasts also display a complex substructure where kink bands $(0.5-1 \mathrm{~mm}$ wide) at high angles to albite twins overprint, and are deformed by subgrain boundaries (Pl. 3, Figs. 2, 4). Porphyroclast margins are commonly irregular and serrated, and are enveloped by recrystallized plagioclase (core and mantle structure; White, 1976). Plagioclase neoblasts have a moderate-to-strong, shape-preferred orientation and a strong crystallographic preferred orientation. Neoblast grain boundaries are weakly to highly serrated. Forming mantles (100-500 $\mu \mathrm{m}$ wide) around plagioclase porphyroclasts, neoblasts display undulose extinction and evidence for subgrain formation (see above). Some plagioclase neoblasts have formed by the migration of kink-band boundaries. This mechanism may produce rare intragranular shear Zones 1-5 neoblasts wide that deform some porphyroclasts. Plagioclase neoblast grain size is significantly smaller than the weakly or moderately recrystallized textures $(91 \mu \mathrm{m}$; Table 2$)$. Up to $50 \%$ of plagioclase neoblasts are twinned. Subgrains $(70 \mu \mathrm{m})$ are concentrated around the margins $(300-500 \mu \mathrm{m}$ wide) of plagioclase porphyroclasts. Less commonly, subgrains are found in the central regions of porphyroclasts.

Olivine porphyroclasts (with aspect ratios range from 1:1 to 1:6) have a weak-to-moderate, shape-preferred orientation. Stringers of olivine neoblasts, extending from the tails of olivine porphyroclasts, are dispersed subparallel to the foliation and have a moderate crystallographic preferred orientation (Pl. 3, Fig. 3). Olivine neoblast grain size is $115 \mu \mathrm{m}$. As in the previous textures, olivine subgrains of similar dimensions to olivine neoblasts are also evident where kink bands are misaligned by subgrain rotation.

Clinopyroxene exsolution lamellae are commonly bent by kink bands ( $1 \mathrm{~mm}$ wide) oriented at high angles to the foliation (Pl. 3, Fig. $5)$. The margins $(300-500 \mu \mathrm{m}$ wide) of clinopyroxenes are recrystallized and the porphyroclast boundaries are weakly serrated. Neoblast grain size is similar to the moderately recrystallized texture $(76 \mu \mathrm{m}$; Table 2). A few rare intragranular shear zones, one to two neoblasts wide, also deform clinopyroxene grains. Clinopyroxene neoblasts generally do not have a preferred orientation except as aggregates in pressure shadow regions in porphyroclast tails and occasional stringers.

\section{Mylonitic Texture}

Mylonitic textures are commonly spatially gradational with the porphyroclastic textures and are most abundant in Hole 923A (Pl. 4). The most significant difference between this texture and the porphyroclastic texture is the more extensive clinopyroxene recrystallization (generally $>70 \%$ and over $90 \%$ recrystallized in some samples) (Pl. 4 , Figs. 1-3). Olivine is $>50 \%$ recrystallized. Mylonitic textures are characterized by a strong foliation and, in some cases, a lineation. In core samples, the foliation and the lineation are most clearly defined by clinopyroxene crystals. Optical microscopy reveals planar concentrations of recrystallized olivine and clinopyroxene, aligned parallel to the margins of the shear zone and in rare shear bands, about $30^{\circ}$ oblique to the margins. Typical "type I" S-C mylonitic fabrics, in which narrow zones of intense shear strain (C-surfaces) cut across the mylonitic foliation (S-surfaces) (Berthé et al., 1979; Lister and Snoke, 1984) are not well developed in any of the samples examined in this study. We categorize Sample 153-923A-16R-3, 118-124 cm, as mylonitic because of its fine grain size, strong crystallographic preferred orientation, and serrated grain boundary morphologies (Pl. 4 , Fig. 5). The steep grain-size gradient at the boundary of this mylonitic texture, however, is unusual and is discussed further below.

Plagioclase porphyroclast aspect ratios range from 1:1 to $1: 5$. The core and mantle structure that characterizes the porphyroclastic texture is only locally present. Plagioclase neoblast grain size averages 
Table 2. Distinguishing characteristics of deformation texture categories (for samples in this study only).

\begin{tabular}{|c|c|c|c|c|}
\hline & Weakly recrystallized & Moderately recrystallized & Porphyroclastic & Mylonitic \\
\hline Crystallographic preferred orientation & None & Weak & Moderate to strong & Strong \\
\hline Shape-preferred orientation & None & None & $\begin{array}{l}\text { Variable - moderate to strong neoblast } \\
\text { shape fabrics; porphyroclast aspect } \\
\text { ratios up to 1:10 }\end{array}$ & $\begin{array}{l}\text { Variable-moderate to strong neoblast } \\
\text { shape fabric; porphyroclast aspect } \\
\text { ratios up to } 1: 5\end{array}$ \\
\hline \multicolumn{5}{|l|}{ Recrystallization (\%) } \\
\hline Plagioclase & $<15$ & $15-50$ & $50-70$ & $>70$ \\
\hline Olivine & 10 & $5-20$ & $20-50$ & $>50$ \\
\hline \multirow{2}{*}{\multicolumn{5}{|c|}{ Grain size (mm) }} \\
\hline & & & & \\
\hline Plagioclase neoblasts & $170(10-500)$ & $140(30-510)$ & $90(20-320)$ & $40(10-60)$ \\
\hline subgrains & $125(30-290)$ & $125(30-260)$ & $70(20-180)$ & $50(10-100)$ \\
\hline Olivine neoblasts & $190(60-590)$ & $210(60-480)$ & $115(40-240)$ & $80(20-380)$ \\
\hline subgrains & - & $180(75-350)$ & $120(50-210)$ & $65(10-190)$ \\
\hline Clinopyroxene neoblasts & - & $60(20-200)$ & $76(20-210)$ & $70(10-240)$ \\
\hline Mechanical twinning & Plagioclase & Plagioclase & Plagioclase & Plagioclase \\
\hline Kink bands & Plagioclase, olivine & Plagioclase, olivine & Plagioclase, olivine, clinopyroxene & Plagioclase, olivine, clinopyroxene \\
\hline
\end{tabular}

Notes: Grain-size measurements have not been stereologically corrected and are intended only to indicate differences between textures. Values are based on arithmetic means of 200 counts for each thin section in each textural category. The range of grain sizes is shown in brackets. $-=$ no recrystallization.

$40 \mu \mathrm{m}$. Some mylonitic samples preserve neoblasts with strongly serrated margins, whereas others preserve more equant, polygonal neoblasts. The percentage of twinning in neoblasts is variable, but overall fewer neoblasts are twinned in the finer-grained mylonites than in the other textures $(<30 \%)$. Subgrains are evident in both plagioclase porphyroclasts and neoblasts with an average grain size of $50 \mu \mathrm{m}$. The subgrains do not form distinct rims around porphyroclasts as in the porphyroclastic texture, but are still concentrated at porphyroclast margins (Pl. 4, Fig. 4). Olivine and clinopyroxene have notably finer and more even grain-size distribution in the mylonitic texture than in the other deformation textures (Table 2).

\section{Deformation Textures in Compositionally Distinct Shear Zones}

The textures outlined above are representative for the most of gabbros in this study. A few samples, however, have distinct modal compositions that deserve further comment (see Table 1).

\section{Fe-Ti Oxide Gabbros}

In the least-deformed specimens, primary Fe-Ti oxides occur as interstitial euhedral grains evenly dispersed on a thin-section scale. Secondary Fe-Ti oxides in the weakly deformed samples occur as exsolution products of clinopyroxene and are commonly dispersed in brown and green amphibole rims where clinopyroxene has been hydrothermally altered. In some mylonitic and porphyroclastic textures (that contain $>50 \%$ oxides in some cases), veins of concentrated $\mathrm{Fe}$ Ti oxides (magnetite and ilmenite) cut the dynamic recrystallization textures. Fragments of dynamically recrystallized plagioclase and clinopyroxene are also suspended within the veins. The Fe-Ti oxide grains within these veins typically have straight grain boundaries and are relatively large (about $200-500 \mu \mathrm{m}$ ). In contrast, other samples contain $\mathrm{Fe}$-Ti oxide stringers that generally do not cut the plagioclase crystal-plastic fabric. These oxides are finer grained $(<10-150 \mu \mathrm{m})$, with equant, polygonal grain morphologies. In some places such $\mathrm{Fe}$ $\mathrm{Ti}$ oxides invade microcracks in dynamically recrystallized pyroxene grains and are also concentrated in pressure shadows of pyroxene porphyroclast tails and shear bands (for further details and examples, see Agar and Lloyd, (this volume).

\section{Shear Zones Associated with Leucocratic Melt Veins}

In several places deformed and undeformed leucocratic veins cut or have been intruded parallel the crystal-plastic foliation (Cannat, Karson, Miller, et al., 1995). In one sample in this study (153-921E$8 \mathrm{R}-1,91-95 \mathrm{~cm}$ ), a leucocratic vein is barely noticeable within the deformed, coarse-grained, poikilitic texture of the surrounding gabbro (Pl. 5). In thin section, the vein $(0.5-1 \mathrm{~cm}$ wide), dipping at about $50^{\circ}$, cuts the poikilitic gabbro. The contact between the vein and the poikilitic gabbro contains a narrow zone $(<0.5 \mathrm{~mm})$ of weak undulatory extinction devoid of any twins or grain boundaries along the margin of wallrock plagioclase grains (Pl. 5, Fig. 1). This zone has a serrated boundary which overprints the strongly twinned interior of the wallrock plagioclase porphyroclast.

The vein fill comprises euhedral, strongly zoned plagioclase $\left(\sim \mathrm{An}_{27}-\mathrm{An}_{32} ; 40 \%-50 \%\right)$ with abundant melt inclusions in crystal cores (Pl. 5, Fig. 2). The vein is comparatively rich in Fe-Ti oxide phases (up to $10 \%$ in places). Some of the Fe-Ti oxides formed as exsolution products of clinopyroxene porphyroclasts and form dark rims around the edges of amphibole alteration haloes. Fe-Ti oxides are also concentrated along the margins of the shear zone, but do not appear to be associated with any particular phase. The plagioclase crystals in the vein are generally equidimensional, with grain sizes ranging from $<50 \mu \mathrm{m}$ to about $350 \mu \mathrm{m}$. About $50 \%$ of the plagioclase grains display albite twinning, usually in a central core, but in some cases over the entire crystal. The optical zoning in some plagioclase crystals appears to be truncated by adjacent, indenting grains. Interstitial quartz $(20 \%-30 \%)$ surrounds plagioclase with weakly sutured grain boundaries. Clasts of the wallrock plagioclase and pyroxene have been fractured and incorporated into the vein. Green amphibole alters the pyroxene porphyroclasts within the leucocratic vein, but not those in the wallrock.

\section{PETROFABRIC ANALYSIS}

Two contrasting deformation textures were investigated by universal-stage analysis of plagioclase petrofabrics. One analysis was undertaken on a mylonitic shear zone (Sample 153-923A-15R-1, $117-123 \mathrm{~cm}$ ) and a second on the leucocratic vein associated with a shear zone described above (Sample 153-921E-8R-1, 91-95 cm). Compositional analyses of Sample 153-923A-15R-1, 117-123 cm, show a range of plagioclase neoblast anorthite $(\mathrm{An})$ compositions ranging from $A n_{45}$ to $A n_{71}$ with a similar range $\left(\mathrm{An}_{42}-\mathrm{An}_{73}\right)$ in porphyroclasts. In Sample 153-921E-8R-1, 91-95 cm, the compositions of cores of the grains used for optical fabrics range from $\mathrm{An}_{27}$ to $\mathrm{An}_{32}$. Some of the grains are strongly zoned, but the detailed compositional variations have not yet been investigated.

The optical indicatrix axes and the poles to (010) planes (albite twins) in $>100$ grains were measured for each sample following the methods of Wenk et al. (1986). Relating optical indicatrix directions to crystallographic directions in plagioclase is complicated by the fact that the angle between the optical and crystallographic directions changes with composition. For the mylonitic sample, most of the compositional range is within the limits for unambiguous lattice orientation determinations using albite twin planes in conjunction with optic axes (Zhao and Zhao, 1994). For the leucocratic vein, the low 
anorthite content means that unambiguous crystallographic orientations cannot be determined from the albite twin plane alone (or even with two twin planes or cleavages if they were evident). For this study, we therefore indirectly infer crystallographic orientation using the optical indicatrix orientation. This simplifies universal-stage measurements, but also incorporates possible biases in the fabric as the twinned grains may have a stronger preferred orientation than the untwinned ones (Kruhl, 1987).

In Sample 153-923A-15R-1, 117-123 cm (mylonite), no lineation could be identified in the core, and the sample was therefore cut perpendicular to the strike of the shear plane. Sample 153-921E-8R-1, 91-95 cm (leucocratic vein), was cut parallel to the long axis of the core, close to the estimated maximum-dip direction of the vein. The optical indicatrix axes and crystallographic directions were plotted on lower hemisphere stereographic projections, within the specimen reference frame. Plots of the optical indicatrix axes for the two samples are shown in Figure 5. In the mylonitic shear zone, the east-west direction on the plot is parallel to the foliation and perpendicular to the foliation strike. The X-optic axes are oriented within the foliation plane concentrated parallel to its strike, but with some scatter forming a weak east-west girdle (i.e., aligned with the dip of the shear plane). The Y-optic axis fabric shows a similar concentration, with a weak scatter at the north and south of the shear plane. The Z-optic axis and the pole to $(010)$ fabrics are oriented consistently at a high angle to the shear plane. This fabric is typical of plagioclase deformation fabrics from continental tectonites (e.g., Ji et al., 1988; Ji and Mainprice, 1988 ) in which (010) is the dominant slip plane.

In the leucocratic vein (Sample 153-921E-8R-1, 91-95 cm), measurements were made on the central, twinned regions of the grains. The crystallographic data are plotted with the margin of vein oriented east-west. Even though the albite grains have a distinctly euhedral shape (Pl. 5, Fig. 2), there is a crystallographic fabric within the vein. The Z-indicatrix and pole to (010) fabrics form a girdle on the periphery of the plot showing that they are aligned within a plane perpendicular to the vein margin (containing the dip direction). Local maxima occur at about $30^{\circ}$ to the vein margin, but the relatively small number of data means that these maxima are not statistically significant. (Note also that the lower An content of these grains brings the Z-indicatrix axes into closer alignment with the poles to (010) planes). Both the X-and Y-indicatrix axis fabrics have maximum concentrations parallel to the strike of the vein with scattering at low to high angles relative to the vein margin. Some caution needs to be applied to interpreting this fabric as the distribution of the Z-axes may be a function of the angular limits of the universal stage (i.e., steeply plunging axes greater than about $45^{\circ}$ cannot be easily measured). Concentrations of the Z-axes and poles to (010) planes at about $30^{\circ}$ to the inferred shear plane suggest that the girdle is not solely controlled by the mechanics of the universal stage.

\section{MECHANISMS AND CONDITIONS OF DEFORMATION}

The Leg 153 gabbros display clear evidence at a core scale for a polyphase magmatic evolution. Melts were intruded into crystallized wallrocks that had already been deformed under high-temperature, solid-state conditions. The four textural categories assigned here can be broadly related to increasing finite strain on the basis of the extent of recrystallization of the three principal phases (plagioclase, clinopyroxene, and olivine) and the degree of penetrative foliation and lineation. Beyond this, thermal fluctuations may have strongly influenced the microstructural development and preservation during and after deformation. Thus, as always, some caution is necessary in inferring the deformation mechanisms from the microstructures alone.

\section{Subsolidus Deformation Mechanisms}

In the weakly recrystallized texture, the preservation of igneous morphologies in clinopyroxene and most olivine grains indicates very low bulk strains. The strain was accommodated primarily by dislocation glide involving mechanical twins and kink bands in relict plagioclase grains. Recrystallization in the weakly recrystallized texture is indicated by the distinct polygonal morphology of plagioclase neoblasts relative to igneous grains in undeformed samples. In contrast to the relict plagioclase grains, the neoblasts are relatively strain free, as indicated by their lack of undulatory extinction and subgrains. Although many neoblasts contain albite twins, the twins are relatively straight and of constant thickness, resembling growth twins. Combined with a lack of crystallographic and shape-preferred orientation, the neoblast characteristics lead us to infer a static recrystallization mechanism under low differential or hydrostatic stresses. Post-kinematic grain growth may have overprinted dynamically recrystallized grains, but there is now only limited evidence for recovery by climb represented sparse subgrains. We note that the neoblast morphology and twinning are similar to plagioclase grains annealed hydrostatically at $900^{\circ} \mathrm{C}(1 \mathrm{GPa})$ (see fig. 4A in Yund and Tullis, 1991). Although grain growth is not significant over geological time scales below certain critical temperatures, post kinematic grain growth might have been enhanced by the presence of the late-stage melt fraction and locally sustained temperature elevations.

In the moderately recrystallized texture, the more extensive recrystallization of plagioclase and olivine, together with a weak foliation and crystallographic preferred orientation, indicate relatively higher bulk strains. The lack of serrated grain boundaries suggests that either strain-induced grain boundary migration (Bailey and Hirsch, 1962) was not an important recovery mechanism or that a post-deformation grain growth has straightened grain boundaries. In the latter case, however, the static recrystallization was not so extensive that it obliterated deformation twins in plagioclase neoblasts. Although subgrains are not abundant, they indicate some recovery by climb during dislocation creep. The relatively large grain size of the subgrains and neoblasts indicates that differential stress magnitudes were low, but these cannot be fully quantified because of a lack of a suitable calibration.

In the porphyroclastic and mylonitic textures, dislocation creep appears to have been the dominant deformation mechanism in plagioclase. This mechanism is inferred from the presence mechanical twinning and kink bands (dislocation glide) and recovery by both climb and grain boundary migration. Within the both textures, however, there is a wide variation in the extent of subgrain and sutured grain boundary development (or preservation). Samples containing highly serrated grain boundaries with few mechanical twins and strong undulose extinction have a similar appearance to the microstructures of so-called "fast" or free grain boundary migration (Urai et al., 1986). Experimental observations suggest that diffusion creep in feldspar deformation becomes important only in very fine grained aggregates $(2-10 \mu \mathrm{m})$. The samples used in this study do not include ultrafine-grained material, even in the mylonitic samples. Although diffusion creep may operate over coarser grain sizes in natural samples, the moderate-to-strong crystallographic preferred orientation in both the porphyroclastic and mylonitic samples argues against it.

It is possible that grains with areas of irregular and continuous changes in undulatory extinction that are present in all the textures were deformed by submicroscopic cracking (Tullis and Yund, 1987). None of the textures described here, however, contains unambiguous evidence for high-temperature $\left(>550^{\circ} \mathrm{C}\right)$ cataclastic flow (although there are greenschist facies cataclastic zones in the core). The polygonal shape of most recrystallized grains and the similar grain sizes within recrystallized domains argue against a cataclastic origin for finer-grained material in the porphyroclastic and mylonitic fabrics.

\section{Possible Hypersolidus Deformation Mechanisms}

The brecciated appearance of many of the coarse-grained poikilitic gabbros can, in many cases, be simply attributed to rheological contrasts between the plagioclase and clinopyroxene. In other cases, a very similar texture has been generated by the invasion of late-stage 
A

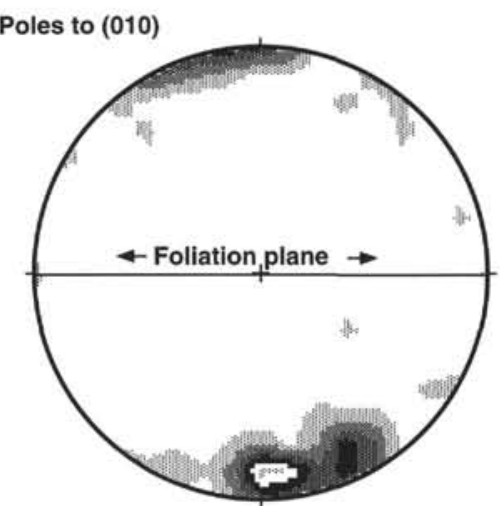

$\mathrm{X}$ optic axes

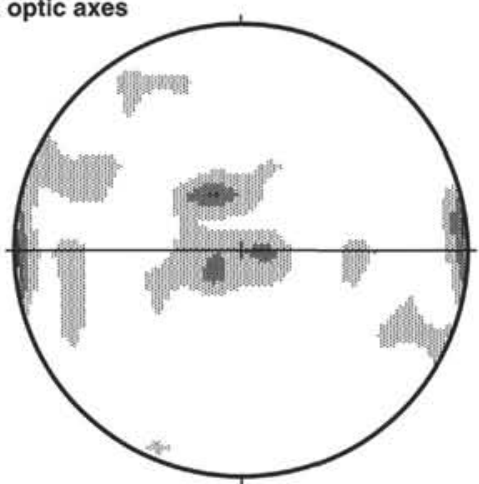

\section{Z optic axes}

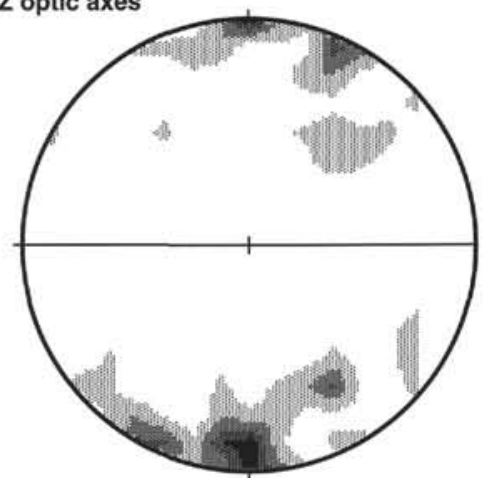

Y optic axes

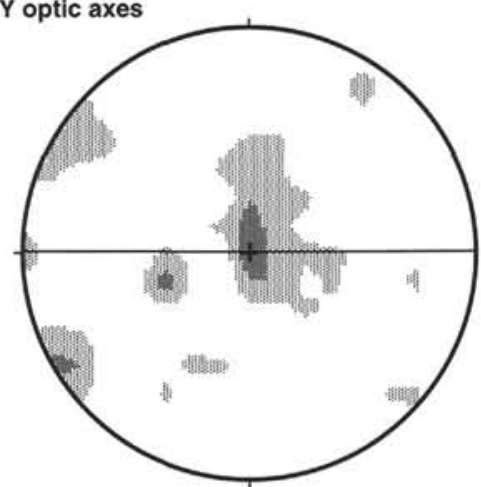

B

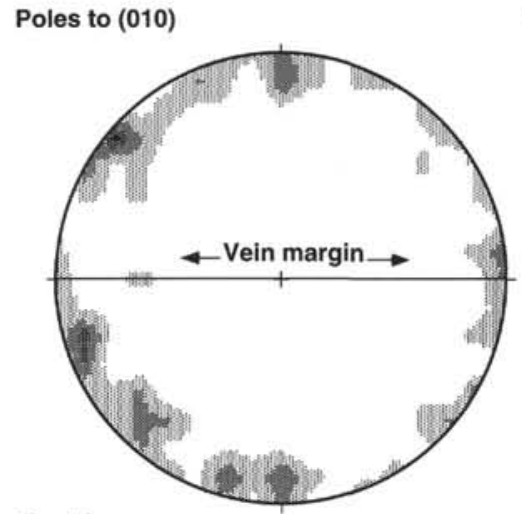

X optic axes

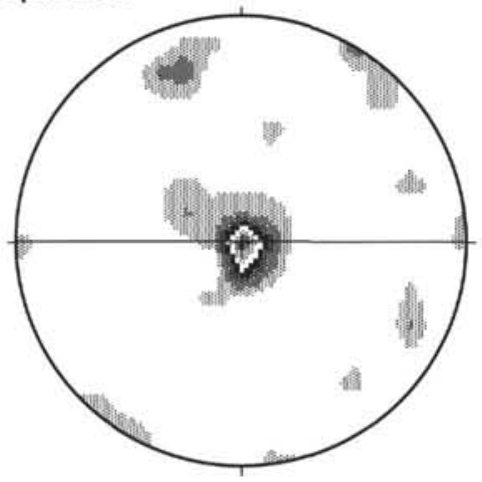

Z optic axes

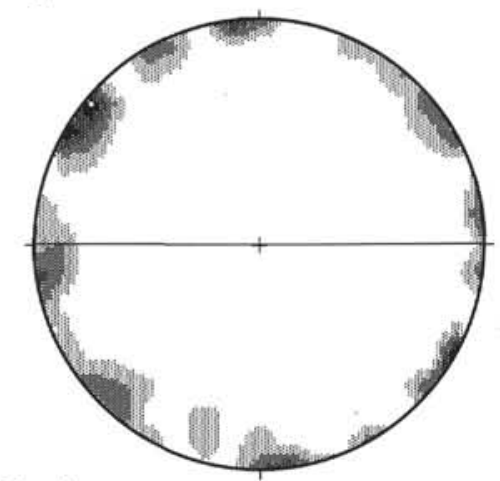

Y optic axes

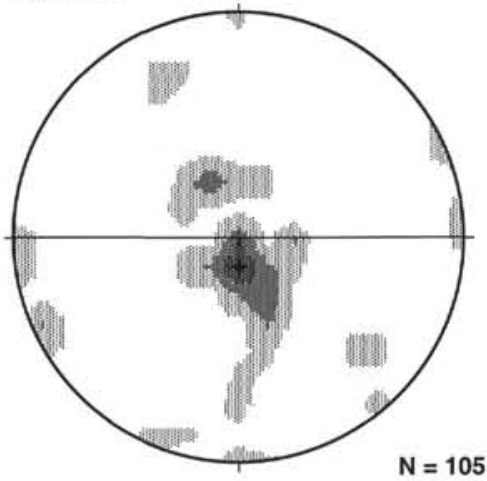

Figure 5. Lower hemisphere, equal-area stereoplots of plagioclase optical and $(010)$ pole fabrics (contouring $1 \%$ area). A. Sample 153-923A-15R-1, 117-122 cm. B. Sample 153-921E-8R-1, 91-95 cm. melts and possible hydrofracturing. In the latter case, the assimilation of host-rock plagioclase during melt injection and subsequent deformation could obliterate evidence for the polyphase magmatic history associated with the shear zone, generating composite geochemical signatures. Confirming synmagmatic deformation in natural samples is fraught with difficulties (e.g., Means and Park, 1994), but we dis- cuss below some textural features that may indicate hypersolidus conditions.

The anomalously sharp boundary of the finest-grained mylonite (Sample 153-923A-16R-3, 118-124 cm) and the even grain-size distribution in all phases in this sample lead us to suggest a possible mixed textural origin involving magmatic intrusion and shearing. 
The sharp boundary resembles an intrusive contact. If this were the case, the fine grain size may be due, in part, to undercooling during intrusion of a melt with a high nucleation density. The observed mix of granoblastic and serrated grain boundaries with moderate-tostrong crystallographic preferred orientation may represent limited dynamic recrystallization caused by shearing during the solidification of a gabbroic dike. Other examples of mylonitic gabbros describe similar sharp boundaries (e.g., Borges and White, 1980), but we note that this particular sample is unusual with respect to other mylonites in the Leg 153 gabbros that have gradational recrystallized grain-size gradients with adjacent porphyroclastic textures.

In the case of the late-stage leucocratic vein (Sample 153-921E$8 \mathrm{R}-1,91-95 \mathrm{~cm}$ ) an intrusive contact is evident and we suggest that shearing occurred during melt intrusion. Grain boundary migration during grain growth in a melt could have generated the truncated compositional zoning in plagioclase grains (e.g., Means and Park, 1994). Based on the lack of grain-scale deformation in albite (euhedral grains with preserved compositional zoning and growth twins) and the presence of a preferred crystallographic orientation, we suggest that grain boundary sliding occurred during crystallization. This mechanism can generate a crystallographic preferred orientation that is controlled by the shape of the plagioclase crystals and their aspect ratios (e.g., Benn and Allard, 1989). Thus, in the leucocratic vein the pole to $(010)$ girdle may represent rolling of grains with their long axes aligned parallel to the shear plane. Textural studies of three mutually perpendicular sections are required to test this interpretation.

Further evidence for synmagmatic deformation textures in oxidebearing shear zones demonstrate a history of dynamic recrystallization, followed by melt invasion sometimes involving fracturing, and continued dynamic recrystallization (Agar and Lloyd, this volume). On the basis of crystallographic fabrics and textural relations in the mylonitic and porphyroclastic textures, it has been suggested that dislocation creep and possibly diffusion creep accommodated deformation. It has also been shown that textural relations that support a synmagmatic origin for several of the oxide-gabbro shear zones (Agar and Lloyd, this volume).

\section{DEFORMATION CONDITIONS}

The polyphase magmatic evolution of the MARK gabbros and their subsequent exhumation complicates comparisons between experimental and natural deformation textures. If an overall down-temperature deformation path is assumed, then a lower temperature limit for dislocation creep in clinopyroxene is constrained by the presence of post-kinematic brown amphibole around recrystallized grain boundaries. Amphibole fibers in the recrystallized tails of clinopyroxene porphyroclasts suggest that some amphibole grew as a synkinematic phase. Amphibole static replacement textures in pyroxene, however, can be difficult to distinguish from synkinematic fibers and are not uniquely diagnostic of growth during deformation. The stability range for the brown amphibole is from $700^{\circ}$ to $900^{\circ} \mathrm{C}$ (Spear, 1981; Liou et al., 1974). Amphibolite-granulite conditions are also supported by experimental data that show that dynamic recrystallization in olivine and clinopyroxene dominates at temperatures above $900^{\circ}-1000^{\circ} \mathrm{C}$ (Kronenberg and Shelton, 1980 ; Mercier, 1985). The observed grain boundary migration recrystallization in plagioclase also supports relatively high-temperature deformation conditions (e.g., Tullis, 1983; Ji and Mainprice, 1990). In addition, subgrain formation in feldspars is generally considered to occur at temperatures in excess of $800^{\circ}-900^{\circ} \mathrm{C}$ for experimental strain rates of $10^{-6} \mathrm{~s}^{-1}$ (e.g., White, 1976; Tullis and Yund, 1987). In natural samples, however, lower strain rates may promote subgrain formation at lower temperatures. Subgrains are not as abundant in the mylonitic textures as in the porphyroclastic textures, possibly because of higher strain rates in the mylonites. On a local scale, the transition from subgrain formation in plagioclase porphyroclast margins to finer-grained neoblasts in the outer mantles may also be caused by a strain-rate increase to- wards the fine-grained plagioclase matrix (e.g., Prior et al., 1990; Pryer, 1993). The green amphibole in post-kinematic veins constrains a lowermost temperature of $450^{\circ} \mathrm{C}$ for the recrystallization of plagioclase. In oxide-bearing shear zones, preliminary geothermometry for magnetite-ilmenite pairs indicates blocking temperatures of about $550^{\circ}$ to $650^{\circ} \mathrm{C}$ (Agar and Lloyd, this volume). The lack of evidence for cataclastic flow suggests that deformation occurred at least above mid-amphibolite conditions (Tullis and Yund, 1987), although this would also depend on the fluid-pressure conditions.

Relative differential stress magnitudes are loosely constrained by the recrystallized grain size for samples in which steady state dislocation creep dominate. Overall, grain-size variations may indicate increasing differential stress magnitudes from the weakly recrystallized to the mylonitic samples (e.g., Twiss, 1977, 1986). We emphasize, however, that the different thermal histories and local strain-rate variations will also affect the grain-size distribution.

\section{WHOLE-ROCK GEOCHEMISTRY}

Based on whole-rock geochemical analyses (Table 3), we display a composite figure of depth variations in $\mathrm{FeO}^{*}$ (total calculated as $\left.\mathrm{FeO} ; \mathrm{FeO}^{*}=\mathrm{Fe}_{2} \mathrm{O}_{3} \cdot 0.8998\right), \mathrm{Mg} \#\left(100 \cdot \mathrm{Mg} /\left[\mathrm{Mg}+\mathrm{Fe}^{*}\right]\right.$, where $\mathrm{Fe}^{*}$ $=\mathrm{FeO} * / 71.85$ ), $\mathrm{Zr}$, and chondrite-normalized $\mathrm{Ti}, \mathrm{La}$, and $\mathrm{Yb}$ (Fig. 6) for all of the holes at Sites 921-923. The crystalline product of fractionated melts are characterized by high $\mathrm{FeO}^{*}$ and low $\mathrm{Mg} \#$ values, as well as high concentrations of incompatible elements (Ti, La, Yb, and $\mathrm{Zr}$ ). Depth plots, (Fig. 6) show that the highest FeO and lowest $\mathrm{Mg} \#$ values are concentrated at the top of the boreholes between 0 and $30 \mathrm{mbsf}$ and within an interval between 60 and $70 \mathrm{mbsf}$. Oxiderich samples are enriched in $\mathrm{FeO}$ and $\mathrm{Ti}$. Incompatible elements (e.g., $\mathrm{Zr}$, Ti, La, and $\mathrm{Yb}$; Fig. 6) are enriched in the same intervals as $\mathrm{FeO}^{*}$ and $\mathrm{Mg \#}$. The increased concentrations are greater than any possible enrichment that can be attributed to cumulate phases alone (Casey, this volume; Irvine, 1981). As the incompatible elements tend to be concentrated in the melt phase, we suggest that high abundances of trapped intercumulus, fractionated melts could account for the enriched zones. This interpretation is compatible with the fact that the enriched zones are also characterized by crosscutting felsic and oxide-gabbro intrusions that appear to represent mobilized intercumulus pore melts (Cannat, Karson, Miller, et al., 1995). Whole-rock Ca\# have no systematic variations with depth (Fig. 7A). Many of the most extreme variations in downhole anorthite content coincide with the locations of shear-zone samples, but the spatial association of shear zones and high residual melt porosity means that these trends are not necessarily controlled by the intensity of deformation. Fractionation of the restite melt during final solidification would produce more sodic plagioclase causing significant variations in An content in the protolith.

Similarly, anorthite contents determined by electron microprobe analyses also have a wide downhole variation ranging from $\mathrm{An}_{12}$ to $\mathrm{An}_{80}$ (Fig. 7B). This is not surprising, given the grain-scale compositional variations revealed by microprobe analyses (Fig. 8). Anorthite contents can vary by more than $30 \%$ between adjacent neoblasts and within porphyroclasts on a millimeter scale. In our sample group there is a tendency for neoblasts in porphyroclast mantles to have a lower anorthite content than their host porphyroclast. This trend contrasts with observations in some feldspathic shear zones in continental settings in which neoblasts have a slightly higher An content (e.g., Olsen and Kohlstedt, 1985). Other studies have shown that recrystallized grain compositions are influenced by the original composition of the porphyroclast and may become either more sodic or more calcic (Borges and White, 1980). Backscatter electron imaging also reveals an alteration that overprints the recrystallization, generating patchy variations in atomic number that cut across recrystallized grain boundaries (Fig. 8). The variations in atomic number contrast correspond directly to variations in the anorthite content of the plagioclase. 
Table 3. Whole-rock geochemical analyses.

\begin{tabular}{|c|c|c|c|c|c|c|c|c|c|c|c|}
\hline Hole, core, section: & 921B-3R-2 & $921 \mathrm{~B}-4 \mathrm{R}-2$ & $921 \mathrm{D}-4 \mathrm{R}-1$ & $921 \mathrm{D}-4 \mathrm{R}-1$ & $921 \mathrm{D}-5 \mathrm{R}-2$ & 921E-3R-1 & $921 \mathrm{E}-8 \mathrm{R}-1$ & 921E-8R-1 & 921E-8R-1 & $922 \mathrm{~A}-2 \mathrm{R}-1$ & $922 \mathrm{~A}-2 \mathrm{R}-5$ \\
\hline Interval $(\mathrm{cm})$ : & $43-46$ & $71-76$ & $36-43$ & $59-63$ & $68-73$ & $66-72$ & $78-80$ & $91-95$ & $118-125$ & $83-87$ & $85-90$ \\
\hline Lithology: & Gabbro & $\begin{array}{l}\text { Olivine } \\
\text { gabbro }\end{array}$ & Gabbro & Gabbro & Gabbro & Gabbro & Gabbro & Gabbro & $\begin{array}{l}\text { Olivine } \\
\text { gabbro }\end{array}$ & Gabbro & Gabbro \\
\hline Depth (mbsf): & 26.40 & 36.31 & 29.66 & 29.89 & 41.03 & 20.46 & 69.78 & 69.91 & 70.18 & 7.43 & 12.79 \\
\hline${ }^{87} \mathrm{Sr} /{ }^{86} \mathrm{Sr}:$ & & 0.702361 & 0.702371 & & & 0.702592 & & & & & \\
\hline \multicolumn{12}{|l|}{ Major elements (wt\%) } \\
\hline $\mathrm{SiO}_{2}$ & 50.64 & 47.47 & 48.28 & 45.37 & 50.53 & 51.10 & 54.54 & 52.39 & 47.80 & 45.76 & 44.15 \\
\hline $\mathrm{TiO}_{2}$ & 0.30 & 0.14 & 1.83 & 4.28 & 0.29 & 0.36 & 1.76 & 0.50 & 0.19 & 0.81 & 2.66 \\
\hline $\mathrm{Al}_{2} \mathrm{O}_{3}$ & 17.20 & 21.16 & 15.12 & 11.48 & 17.47 & 16.68 & 18.14 & 16.19 & 19.76 & 17.44 & 14.34 \\
\hline $\mathrm{Fe}_{2} \mathrm{O}_{3}$ & 6.73 & 6.08 & 10.71 & 15.32 & 5.62 & 5.82 & 8.86 & 5.38 & 5.55 & 10.78 & 15.34 \\
\hline $\mathrm{MnO}^{3}$ & 0.12 & 0.09 & 0.18 & 0.26 & 0.10 & 0.11 & 0.17 & 0.11 & 0.09 & 0.16 & 0.24 \\
\hline $\mathrm{MgO}$ & 10.24 & 12.75 & 8.35 & 8.95 & 9.46 & 9.52 & 4.13 & 8.16 & 10.77 & 14.58 & 6.91 \\
\hline $\mathrm{CaO}$ & 12.91 & 11.03 & 11.43 & 12.34 & 13.62 & 12.38 & 8.39 & 13.40 & 12.26 & 9.19 & 11.69 \\
\hline $\mathrm{Na}_{2} \mathrm{O}$ & 2.54 & 2.30 & 3.00 & 2.19 & 2.38 & 2.74 & 5.25 & 3.03 & 2.15 & 1.96 & 2.36 \\
\hline $\mathrm{K}_{2} \mathrm{O}$ & 0.06 & 0.06 & 0.01 & 0.05 & 0.04 & 0.04 & 0.12 & 0.08 & 0.00 & 0.05 & 0.05 \\
\hline $\mathrm{P}_{2} \mathrm{O}_{5}$ & 0.02 & 0.02 & 0.00 & 0.57 & 0.03 & 0.02 & 0.55 & 0.06 & 0.02 & 0.20 & 1.07 \\
\hline Total & 100.76 & 101.10 & 98.91 & 100.82 & 99.55 & 98.77 & 101.92 & 99.30 & 98.59 & 100.92 & 98.81 \\
\hline LOI & 1.00 & 0.96 & 1.61 & 2.01 & 0.83 & 0.55 & 0.46 & 0.89 & & 0.76 & 0.53 \\
\hline \multicolumn{12}{|l|}{ Trace elements (ppm) } \\
\hline V & 130.3 & 55.2 & 313.4 & 508.8 & 120.5 & 146.9 & 109.9 & 145.0 & 88.0 & 71.6 & 391.7 \\
\hline $\mathrm{Ti}$ & 1824.3 & 856.1 & 10970.9 & 25674.8 & 1764.3 & 2158.2 & 10562.0 & 3002.9 & 1139.1 & 4830.8 & 15975.5 \\
\hline $\mathrm{Cr}$ & 278.3 & 201.9 & 194.8 & 218.1 & 882.1 & 488.7 & 195.5 & 2210.7 & 600.4 & 147.1 & 554.6 \\
\hline $\mathrm{Ni}$ & 112.8 & 460.0 & 103.2 & 83.7 & 181.8 & 159.6 & 238.3 & 184.4 & 287.6 & 524.0 & 168.6 \\
\hline $\mathrm{Sr}$ & 135.5 & 150.4 & 145.4 & 96.5 & 125.9 & 133.8 & 155.8 & 114.9 & 158.6 & 131.0 & 128.7 \\
\hline $\mathrm{Zr}$ & 17.3 & 17.9 & 41.9 & 97.8 & 37.9 & 57.6 & 727.1 & 1410.5 & 23.1 & 195.9 & 72.6 \\
\hline $\mathrm{Ba}$ & 8.7 & 23.3 & 20.3 & 9.5 & 9.2 & 19.3 & 22.8 & 14.4 & 16.5 & 11.3 & 13.5 \\
\hline $\mathrm{Sc}$ & 35.4 & 9.1 & 46.8 & 54.2 & 29.5 & 35.1 & 24.0 & 38.0 & 18.4 & 9.3 & 38.4 \\
\hline $\mathrm{Y}$ & 9.0 & 2.8 & 20.3 & 53.4 & 8.0 & 22.1 & 125.3 & 55.1 & 5.8 & 26.5 & 69.7 \\
\hline $\mathrm{La}$ & 0.41 & 0.64 & 1.27 & 3.17 & 0.23 & 2.80 & 15.17 & 3.97 & 0.96 & 3.16 & 5.68 \\
\hline $\mathrm{Ce}$ & 1.78 & 2.47 & 4.82 & 12.92 & 1.77 & 9.09 & 50.95 & 14.01 & 3.34 & 10.93 & 21.74 \\
\hline $\mathrm{Nd}$ & 1.57 & 0.88 & 4.23 & 15.0 & 41.20 & 6.35 & 49.96 & 13.59 & 1.78 & 10.13 & 24.24 \\
\hline $\mathrm{Sm}$ & 0.63 & 0.26 & 1.55 & 5.33 & 0.50 & 2.03 & 15.27 & 4.54 & 0.56 & 3.09 & 8.09 \\
\hline $\mathrm{Eu}$ & 0.46 & 0.26 & 1.09 & 2.08 & 0.32 & 0.66 & 4.49 & 1.77 & 0.45 & 1.18 & 2.38 \\
\hline Gd & 1.00 & 0.31 & 2.29 & 7.71 & 0.83 & 2.67 & 19.11 & 6.22 & 0.73 & 3.86 & 11.08 \\
\hline Dy & 1.46 & 0.40 & 3.20 & 8.95 & 1.23 & 3.32 & 20.58 & 8.30 & 0.88 & 4.25 & 11.94 \\
\hline $\mathrm{Er}$ & 0.88 & 0.24 & 2.15 & 5.38 & 0.74 & 2.26 & 12.46 & 6.34 & 0.59 & 2.64 & 6.89 \\
\hline $\mathrm{Yb}$ & 0.77 & 0.31 & 2.08 & 4.40 & 0.65 & 2.18 & 10.66 & 6.50 & 0.60 & 2.35 & 5.28 \\
\hline $\mathrm{Lu}$ & & 0.03 & 0.33 & & & 0.33 & & & 0.08 & & \\
\hline
\end{tabular}

\section{ISOTOPIC ANALYSES}

Whole-rock ${ }^{87} \mathrm{Sr} /{ }^{86} \mathrm{Sr}$ ratios were analyzed in an attempt to establish the extent to which samples from within deformation zones were characterized by enhanced fluid flow and alteration effects, with respect to other gabbroic samples from outside the deformed zones. These results (Table 4) are surprising in that there is little difference in the ${ }^{87} \mathrm{Sr} /{ }^{86} \mathrm{Sr}$ ratios from gabbros sampled within and outside the deformed zones. All samples tend to lie close to the magmatic value of $\sim 0.70235$. Figure 9 shows a comparison of results between samples used for this study and those derived from a study of the freshest samples in the cores (Kempton and Hunter, this volume). We note that the slight differences between the samples studied here, which range from 0.702311 to 0.702611 , could be loosely correlated with volatile loss on ignition (LOI) and the extent of alteration (Fig. 10), but it is not statistically significant. From whole-rock geochemistry, there are no apparent systematic trends between LOI values and the distribution of elements likely to be mobilized by hydrothermal alteration or depth.

Kempton and Hunter (this volume) show that plagioclase separates and their leachates show a near constant value of 0.70235 , interpreted to represent a magmatic ${ }^{87} \mathrm{Sr} /{ }^{86} \mathrm{Sr}$ value. The clinopyroxenes showed somewhat higher ratios $(0.70240-0.70245)$ and the leachates showed values of $0.704-0.705$. The higher values are apparently associated with marginal clinopyroxene alteration. More extensive hydrothermal alteration is to be expected in pyroxene than plagioclase because plagioclase has high $\mathrm{Sr}$ concentration (less easily altered) in comparison to the low $\mathrm{Sr}$ concentration in clinopyroxene (easily altered).

The range of Nd-isotope values is within the range of primary values presented in Kempton and Hunter (this volume) (Fig. 11). The relative immobility of rare-earth elements during seawater alteration means that significant variations in $\mathrm{Nd}$-isotope values would not be expected. If infiltrating melts had a significantly different Nd-isotope composition from the host gabbroic cumulate then a wider range of $\mathrm{Nd}$ values would be expected. The results of this study and that of Kempton and Hunter, however, indicate that the MARK gabbros are very homogeneous with respect to $\mathrm{Nd}$ ratios.

In contrast, excluding samples that show a strong $\mathrm{Pb}$-isotope disequilibrium between coexisting plagioclase and clinopyroxene (see Kempton and Hunter, this volume), the whole-rock samples analyzed in this study all have significantly more radiogenic $\mathrm{Pb}$-isotope ratios than the primary magmatic values determined from leached mineral separates (Fig. 12). This suggests that unleached samples contain a radiogenic $\mathrm{Pb}$-isotope component of secondary origin that is removed (at least partially) during leaching. The leachates in the study by Kempton and Hunter were consistently more radiogenic than the mineral residues (with the exception of the intervals showing mineral isotope disequilibrium). The overlap between the leachate analyses and the whole-rock analyses (this study) suggests that the $\mathrm{Pb}$ isotopic composition may be dominated by a leachable component. The $\mathrm{Pb}$ isotopes may therefore be more sensitive to secondary processes than $\mathrm{Nd}$ and possibly $\mathrm{Sr}$.

\section{DISCUSSION}

The results of our comparative analyses do not reveal any distinct correlations between deformation state, whole-rock geochemistry, and isotopic signatures. Yet, the chemical modification of shear zones has been well documented in other settings (e.g., Beach, 1980; Brown et al., 1980; Potdevin et al., 1989; Kerrich et al., 1987) and there is evidence of fluid exchange and alteration in the samples. We discuss our results in the light of this apparent contradiction.

Based on the microstructural relations, dynamic and static recrystallization in the samples used in this study occurred at relatively high temperatures, probably $>700^{\circ} \mathrm{C}$. Deformation was accommodated primarily by dislocation creep. It is possible that some recrystalliza- 
Table 3 (continued).

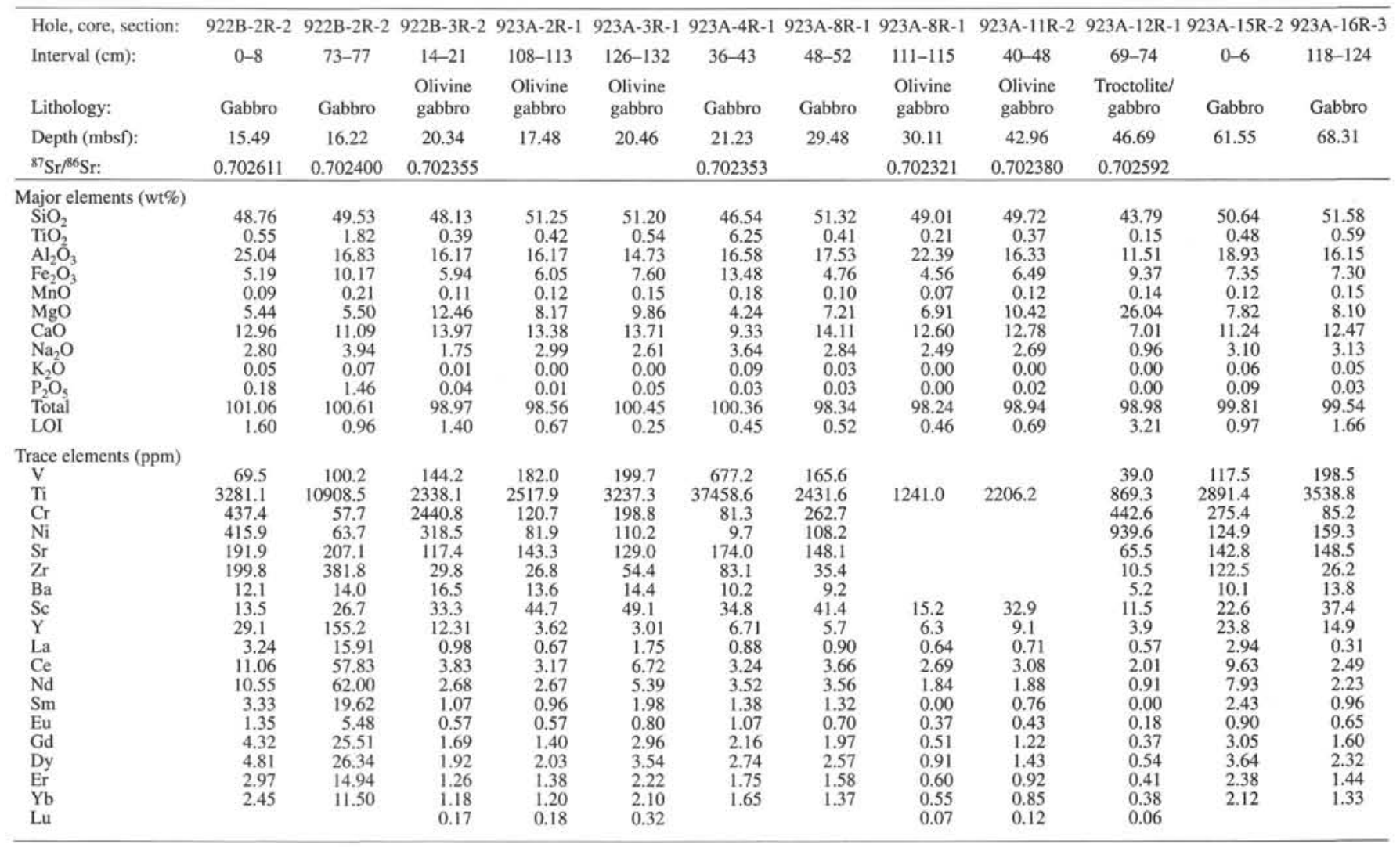

tion of plagioclase occurred at lower temperatures $\left(>450^{\circ} \mathrm{C}\right)$, but we would expect more evidence for synkinematic cracking of olivine and pyroxene during bulk deformation at these temperatures. Thus we suggest that most of the deformation in our samples ceased under upper amphibolite facies conditions during which brown amphibole was precipitated around the pyroxene-recrystallized grain boundaries. During this high-temperature deformation, crosscutting relations indicate that late-stage magmatic fractionates were mobilized into deformed regions (that may have still been deforming). Possible synkinematic shearing at hypersolidus conditions may have generated the crystallographic preferred orientations that we observe in the leucocratic vein discussed above. The introduction of fractionated melts changed the bulk composition of the deformed (or deforming) regions.

Only minor strains occurred in our samples during amphibolite to greenschist facies conditions, as supported by the presence of undeformed, small-aperture actinolite/chlorite veins that cut the recrystallization fabrics. We did not study the cataclastic zones obtained during Leg 153 in which extensive synkinematic hydrothermal alteration has occurred, primarily at greenschist facies (Cannat, Karson, Miller, et al., 1995). Some of the cataclastic zones are located within less than a meter of our samples, but the greenschist facies alteration in these samples is volumetrically low, $<10 \%$ in many cases. Permeability was therefore extremely heterogeneous on scales of $<1 \mathrm{~m}$, and some samples, which are virtually unaltered, appear to have been largely isolated from seawater circulation.

The low, near magmatic values of the ${ }^{87} \mathrm{Sr} /{ }^{86} \mathrm{Sr}$ ratios in all the deformed samples could indicate that fluid flow of a ${ }^{87} \mathrm{Sr} /{ }^{86} \mathrm{Sr}$-enriched (seawater-like) hydrothermal fluid did not occur within the sheared samples. On the other hand, mineral chemistry studies show extreme variations in the anorthite content of porphyroclasts and neoblast within shear zones. The plagioclase compositional variations can be explained by diffusion during recrystallization and primary magmatic variations. Many of the samples analyzed are also characterized by marginal hydrous alteration phases around porphyroclastic or recrystallized primary phases. These hydrothermal phases and microstructural relations show that aqueous fluid did interact with our samples, but primarily after deformation. We suggest that the ${ }^{87} \mathrm{Sr} /{ }^{86} \mathrm{Sr}$ composition of the exchanged fluid was buffered by a substantial overlying rock column.

Synthetic profiles resulting from $\mathrm{Sr}$-isotope exchange modeling and expected alteration effects for bulk-rock samples have been constructed using porosity and permeability relationships for young (5.9 m.y. old) oceanic crust (E. Rutherford and J.F. Casey, unpubl. data) in ODP Hole 504B (e.g., Becker, 1989) for varying exchange efficiencies (Fig. 13). The synthetic profiles show a common pattern of rapidly decreasing whole-rock ${ }^{87} \mathrm{Sr} /{ }^{86} \mathrm{Sr}$ with depth. This pattern results from the fact that, as reactions take place at shallow levels, the fluid changes composition toward the original magmatic composition of the overlying rock column. Various exchange efficiencies (a factor to limit the degree of exchange of $\mathrm{Sr}$ atoms, i.e., the reaction completion per increment of alteration) result in various shapes for the alteration profiles (Fig. 13A). An efficiency factor of 0.25 typically fits ${ }^{87} \mathrm{Sr} /{ }^{86} \mathrm{Sr}$ profiles in oceanic crust and ophiolites (Rutherford, 1993; E. Rutherford and J.F. Casey, unpubl. data). Figure 13B shows the effect of duration of alteration, which can act to shift values higher, but note the sharp downward decreases in ratios are maintained. Thus, if samples were exposed to seawater circulation at deep levels in the crust, significant shifts in ${ }^{87} \mathrm{Sr} /{ }^{86} \mathrm{Sr}$ values from magmatic toward seawater ratios would not be expected, even if fluid flow was enhanced in the shear zones. Losses on ignition between 0.46 and $3.2 \mathrm{wt} \%$ also suggest alteration by aqueous fluids. Significant fluid-related metasomatic effects were thus likely, even though they are not apparent from ${ }^{87} \mathrm{Sr} /{ }^{86} \mathrm{Sr}$ ratios. The data may therefore indicate that high-tem- 

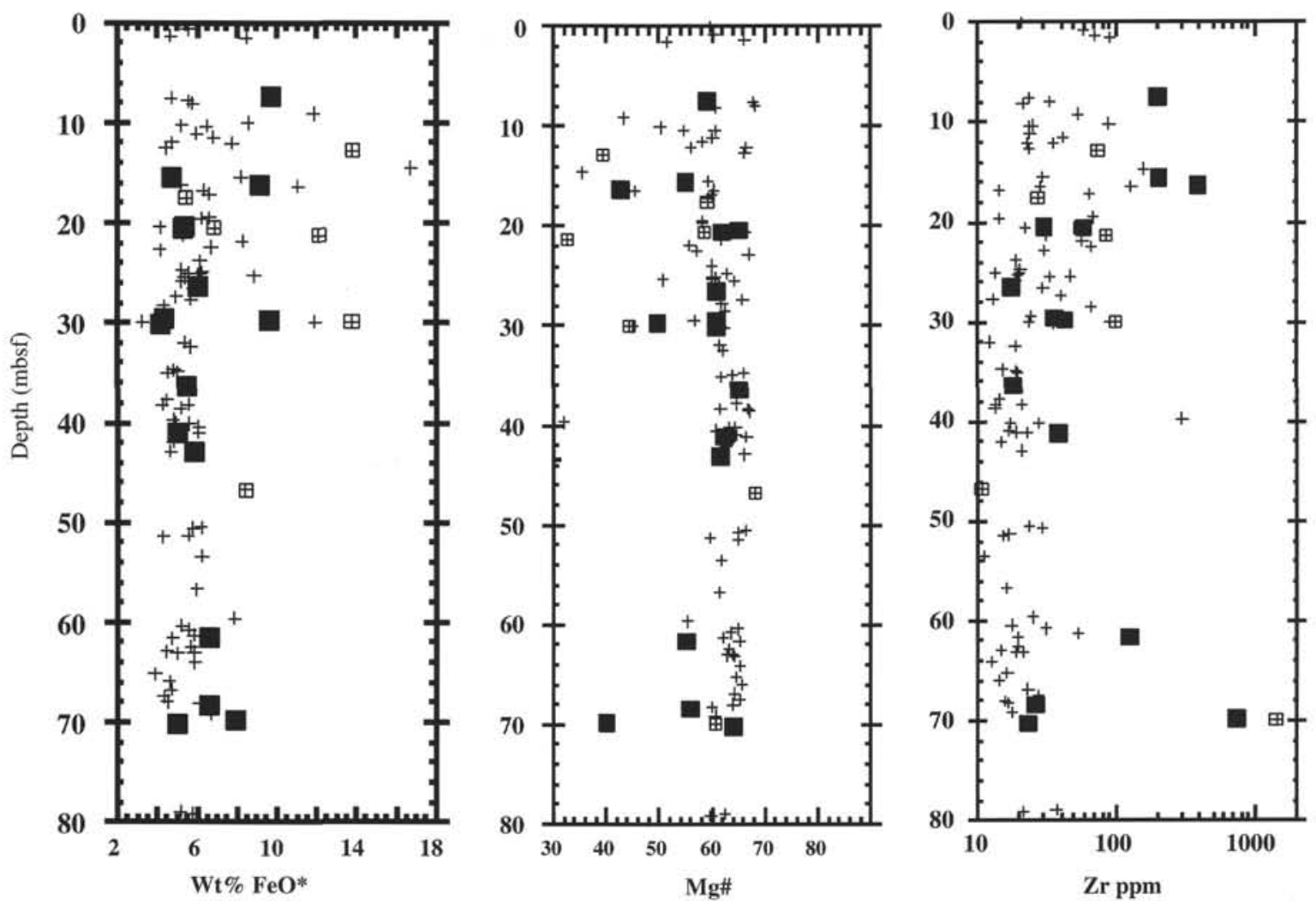

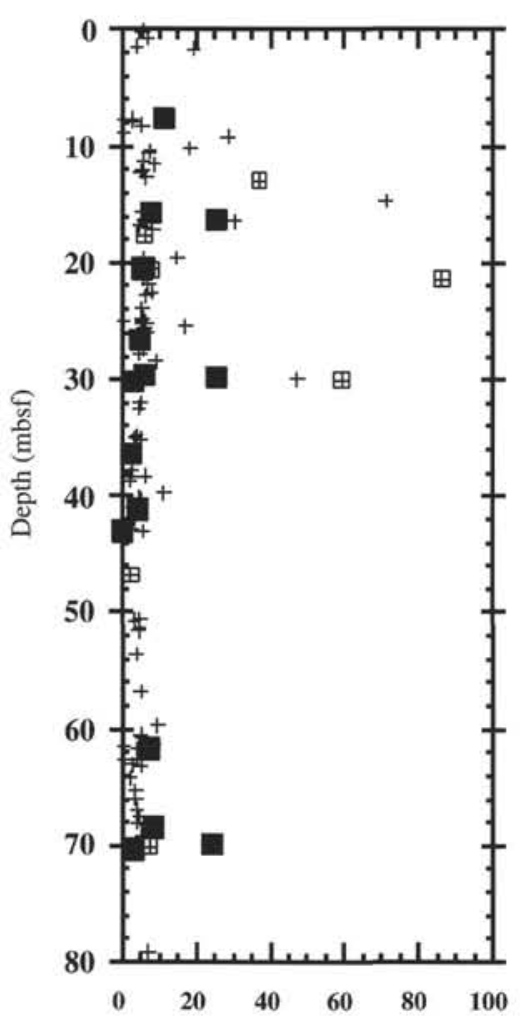

(Ti)en

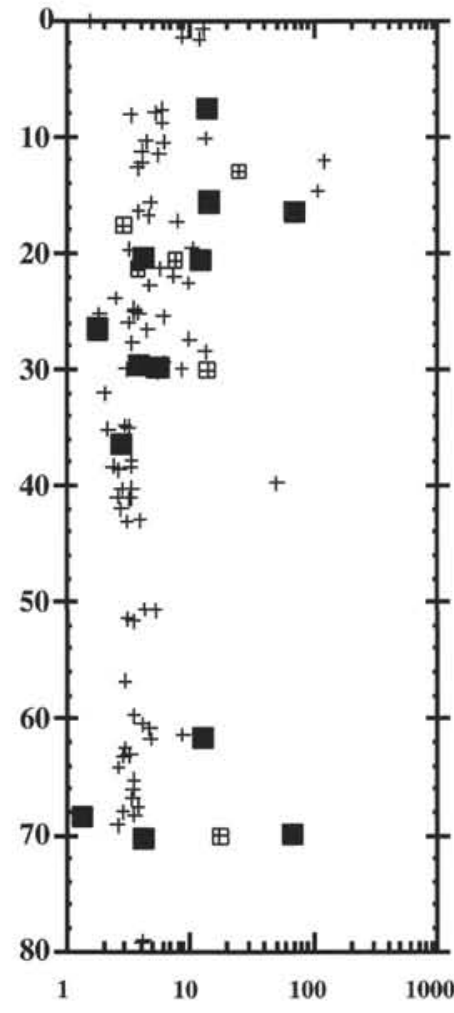

(La)en

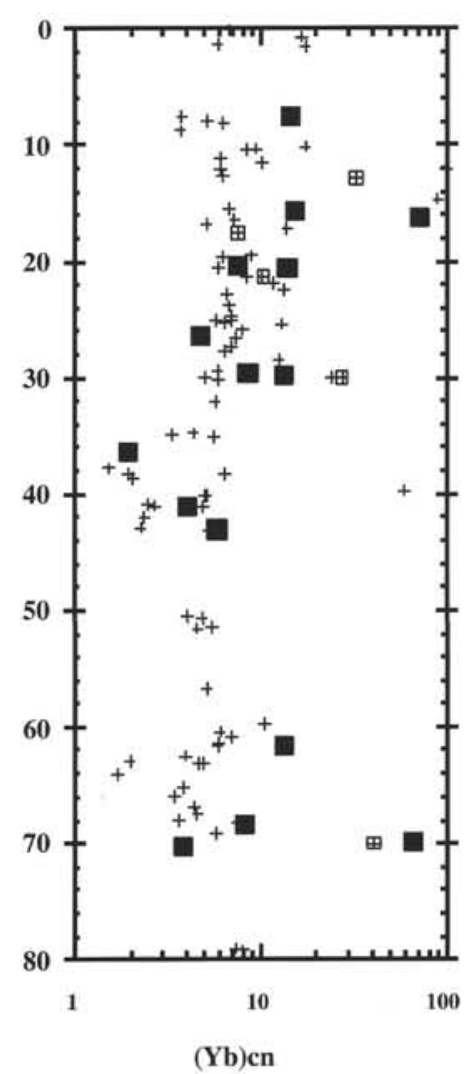

Figure 6. Downhole variations of $\mathrm{FeO} *$ (total $\mathrm{FeO}$ ), $\mathrm{Mg \# ,} \mathrm{Zr}$ (ppm), and chondrite-normalized ( $\mathrm{cn}$ ) $\mathrm{Ti}, \mathrm{La}$, and $\mathrm{Yb}$ for samples in this study (squares) and other samples not included in this study (crosses). Open squares represent weakly and moderately recrystallized samples. Solid squares represent porphyroclastic and mylonitic samples. 
A

Hole 923A

Plagioclase

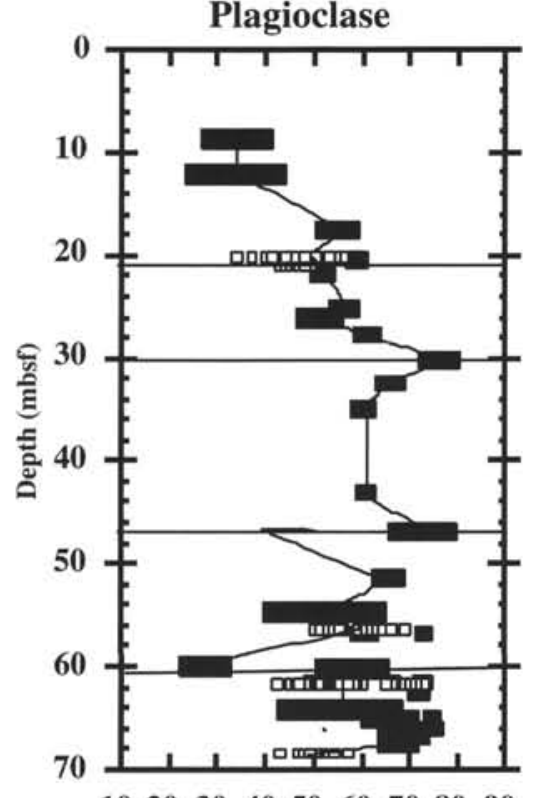

$\begin{array}{lllllllll}10 & 20 & 30 & 40 & 50 & 60 & 70 & 80 & 90\end{array}$

Anorthite Content
B

Hole 923A

Whole Rock Analyses

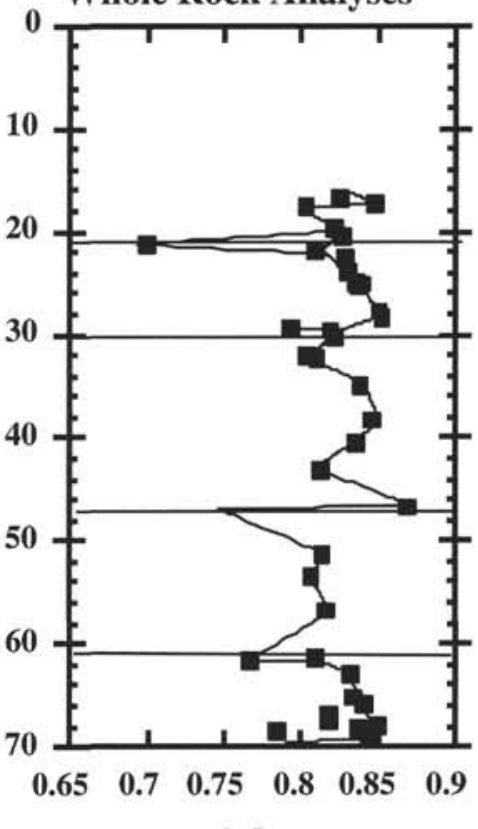

Figure 7. Downhole variations in (A) plagioclase compo-
sition (electron microprobe analyses) and (B) whole-rock Ca\#.
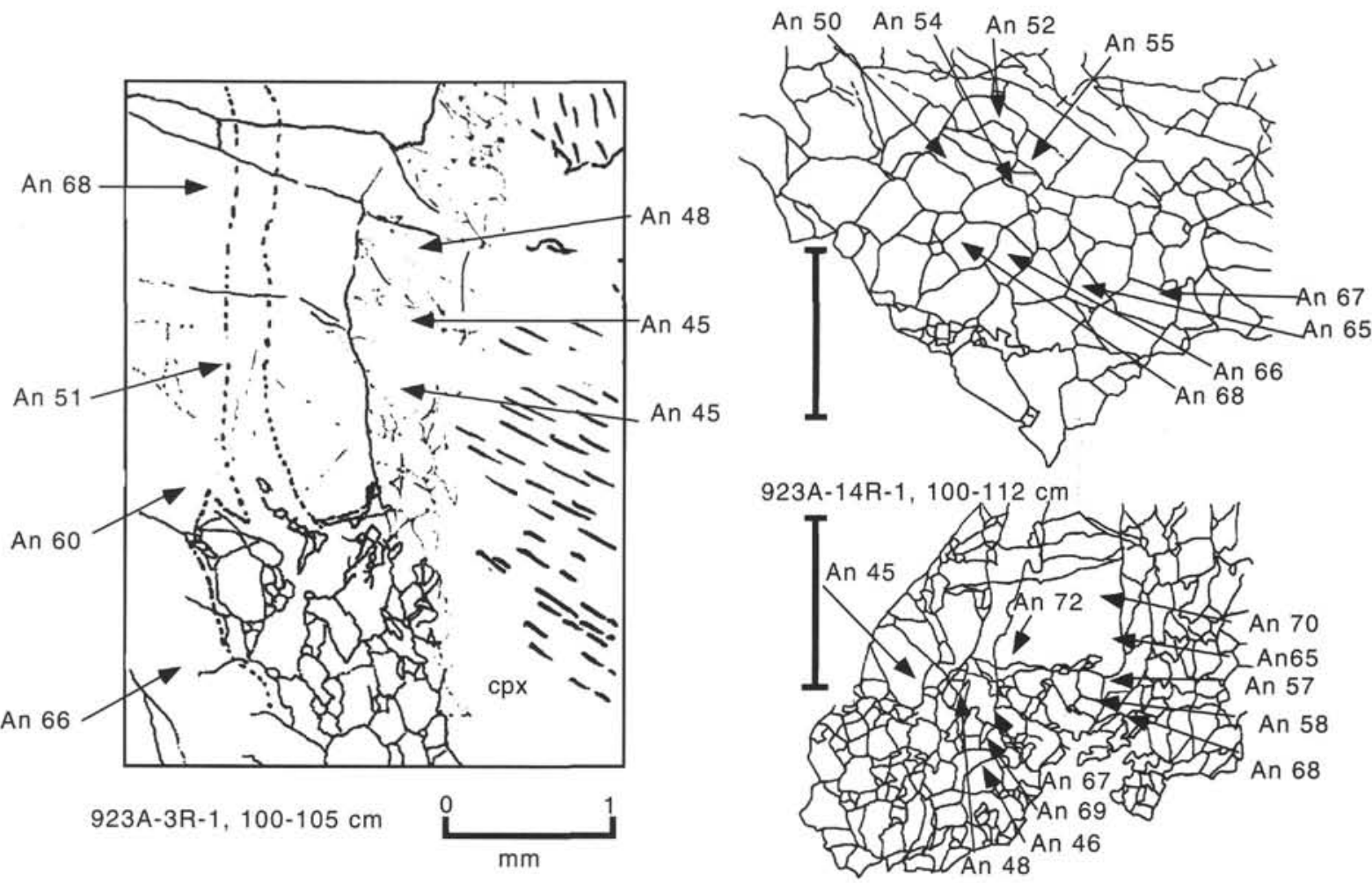

923A-15R-1, 117-122 cm

Figure 8. Line drawings of backscattered electron micrographs showing variations in anorthite content in plagioclase neoblasts (small polygonal grains) and porphyroclasts. Neoblasts tend to have lower An contents than porphyroclasts, for example, compare compositions in the center of the porphyroclast (An ${ }_{51^{-}}$ $\left.\mathrm{An}_{68}\right)$ in Sample 153-923A-3R-1, 100-105 cm, with those in the recrystallized margin $\left(\mathrm{An}_{45}-\mathrm{An}_{48}\right)$ adjacent to a clinopyroxene (cpx) grain. The dotted line encloses an area of lower anorthite content that overprints the deformation fabrics. Adjacent neoblasts can also have very different compositions, for example, in Sample 153-923A015R-1m, 117-122 cm, a grain with a composition of $\mathrm{An}_{48}$ is juxtaposed against a grain with a composition of $\mathrm{An}_{67} . \mathrm{Scale}$ bar $=1 \mathrm{~mm}$. 
Table 4. Results of isotope $(\mathrm{Sr}, \mathrm{Nd}, \mathrm{Pb})$ analyses.

\begin{tabular}{|c|c|c|c|c|c|c|c|c|c|}
\hline Texture & $\begin{array}{l}\text { Depth } \\
\text { (mbsf) }\end{array}$ & $\begin{array}{l}\text { Hole, core, section, } \\
\text { interval }(\mathrm{cm})\end{array}$ & $\begin{array}{l}\text { Analysis } \\
\text { sequence }\end{array}$ & ${ }^{87} \mathrm{Sr} /{ }^{86} \mathrm{Sr}$ & $\begin{array}{l}\text { Average } \\
{ }^{87} \mathrm{Sr} /{ }^{86} \mathrm{Sr}\end{array}$ & ${ }^{143} \mathrm{Nd} /{ }^{144} \mathrm{Nd}$ & ${ }^{206} \mathrm{~Pb} /{ }^{204} \mathrm{~Pb}$ & ${ }^{207} \mathrm{~Pb} /{ }^{04} \mathrm{~Pb}$ & ${ }^{208} \mathrm{~Pb} /{ }^{204} \mathrm{~Pb}$ \\
\hline $\mathrm{P}$ & 36.31 & $921 \mathrm{~B}-4 \mathrm{R}-2,71-76$ & $\begin{array}{l}1 \\
2\end{array}$ & $\begin{array}{l}0.702360 \\
0.702363\end{array}$ & 0.702361 & 0.513197 & 18.283 & 15.523 & 37.713 \\
\hline $\mathrm{P}$ & 29.66 & $921 \mathrm{D}-4 \mathrm{R}-1,36-43$ & $\begin{array}{l}1 \\
2\end{array}$ & $\begin{array}{l}0.702382 \\
0.702360\end{array}$ & 0.702371 & 0.513207 & 18.283 & 15.523 & 37.713 \\
\hline P & 70.18 & $921 \mathrm{E}-8 \mathrm{R}-1,118-125$ & 1 & 0.702611 & 0.702611 & 0.513212 & 18.211 & 15.528 & 37.665 \\
\hline $\mathrm{P}$ & 17.48 & $923 \mathrm{~A}-2 \mathrm{R}-1,108-113$ & $\begin{array}{l}1 \\
2\end{array}$ & $\begin{array}{l}0.702360 \\
0.702351\end{array}$ & 0.702355 & 0.513200 & 18.234 & 15.503000 & 37.641000 \\
\hline WR & 20.46 & $923 \mathrm{~A}-3 \mathrm{R}-1,126-132$ & 1 & 0.702353 & 0.702353 & 0.513237 & 18.190 & 15.500000 & 37.573000 \\
\hline WR & 20.46 & $921 \mathrm{E}-3 \mathrm{R}-1,66-72$ & 1 & 0.702454 & 0.702454 & 0.513209 & 18.127 & 15.493 & 37.537 \\
\hline WR & 20.34 & $922 \mathrm{~B}-3 \mathrm{R}-2,14-21$ & $\begin{array}{l}1 \\
2\end{array}$ & $\begin{array}{l}0.702399 \\
0.702402\end{array}$ & 0.702400 & 0.513184 & 18.194 & 15.519000 & 37.641000 \\
\hline WR & 30.11 & $923 \mathrm{~A}-8 \mathrm{R}-1,111-115$ & 1 & 0.702321 & 0.702321 & 0.513199 & 18.260 & 15.509000 & 37.683000 \\
\hline MR & 42.96 & $923 \mathrm{~A}-11 \mathrm{R}-2,40-48$ & 1 & 0.702380 & 0.702380 & 0.513184 & 18.194 & 15.519000 & 37.641000 \\
\hline WR & 46.69 & $923 \mathrm{~A}-12 \mathrm{R}-1,69-74$ & $\begin{array}{l}1 \\
2\end{array}$ & $\begin{array}{l}0.702596 \\
0.702588\end{array}$ & 0.702592 & 0.513209 & 18.127 & 15.493000 & 37.537000 \\
\hline
\end{tabular}

Note: Abbreviations as in Table 1.

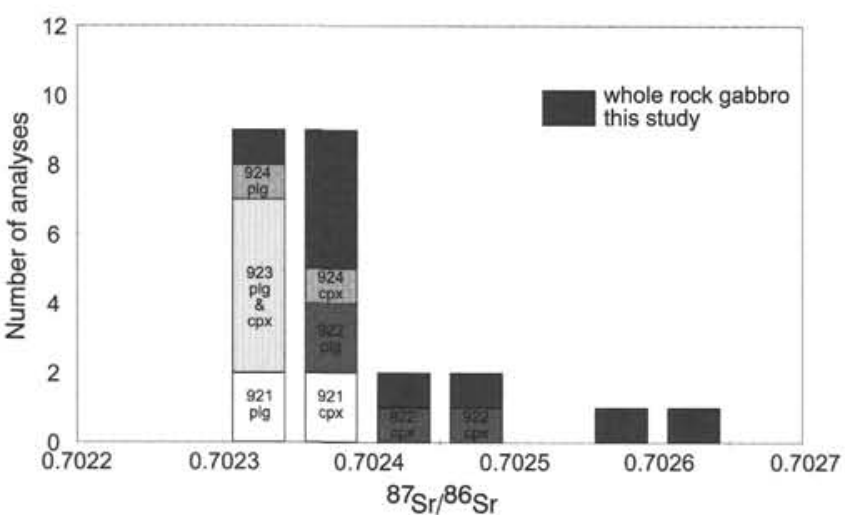

Figure 9. Histogram showing strontium-isotope ratios (see also Table 4). Dark unlabeled regions indicate whole-rock samples analyzed for this study. Shaded and unshaded regions are from mineral separates from the leastaltered samples analyzed by Kempton and Hunter (this volume). Sampled holes and minerals analyzed are labeled for each group of mineral separates. Machine standard NBS 987 gave an average value of $0.710193 \pm 4(1 \sigma)$. Abbreviations: $\mathrm{plg}=$ plagioclase, $\mathrm{cpx}=$ clinopyroxene.

perature deformation took place at significant depths where fluid compositions were almost totally buffered by interaction and exchange with the overlying rock column.

The lack of correlation between $\mathrm{Sr}, \mathrm{Nd}$, and $\mathrm{Pb}$ isotopes with the deformation state of the samples (also noted by Barling et al., this volume) further suggests that isotopic values may be primarily controlled by static, post-deformation alteration. Kempton and Hunter (this volume) have suggested that variations in $\mathrm{Pb}$-isotope ratios may be caused by seawater circulation in which seawater has an elevated $\mathrm{Pb}$ component derived from the overlying sediments.

Geochemical data indicate the presence of late-stage melt fractions, and hence elevated residual melt porosities, particularly in the uppermost core sections (10-30 mbsf and 60-70 mbsf). The high abundances of incompatible elements suggest that the gabbros in these zones went through a final crystallization stage in which there was abundant pore melt (including oxide-rich and silicic compositions). Without deeper samples we cannot say whether the downhole trends are regionally significant. It is possible, however, that the shear zone exposed on the surface of the western flank of the MARK area was generated or nucleated along a melt-laden (oxide-rich) zone that was weak relative to the lower sections. Our evidence indicates that melt mobilization zones are associated with the most intense, high-temperature deformation, supporting our textural interpretations of deformation occurring under near magmatic to hypersolidus conditions. Oxide gabbros and silicic veins are interpreted to repre-

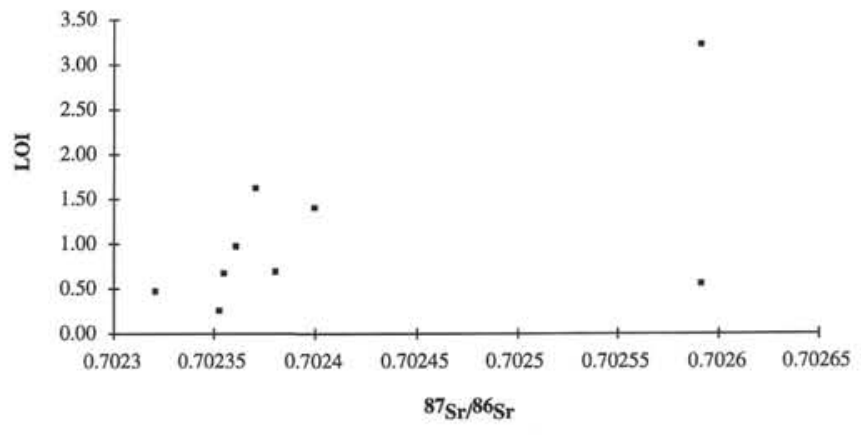

Figure 10. Loss on ignition vs. ${ }^{87} \mathrm{Sr} /{ }^{86} \mathrm{Sr}$.

sent magmas that were mobilized and fractionated within intercumulus pores spaces within the gabbros (Cannat, Karson, Miller, et al., 1995). The focusing of oxide- and quartz-rich assemblages along the shear zones will promote subsequent strain localization along these shear zones during their exhumation or lateral motion away from the ridge axis because of their low-temperature ductile behavior (Agar and Lloyd, this volume).

\section{ACKNOWLEDGMENTS}

We gratefully acknowledge the efforts of the shipboard scientific party during Leg 153 and the editorial review board. The manuscript was improved significantly by a thorough, constructive review by J. Tullis. JOI-USSAC is thanked for supporting one month of postcruise research for S.M. Agar and J.F. Casey. P.D. Kempton was supported by NERC, United Kingdom. J.F. Casey also acknowledges support from NSF-OCE-9204105.

\section{REFERENCES}

Agar, S.M., 1990. Fracture evolution in the upper ocean crust: evidence from DSDP Hole 504B. In Knipe, R.J., and Rutter, E.H. (Eds.), Deformation Mechanisms, Rheology and Tectonics. Geol. Soc. Spec. Publ. London, 54:41-50.

1991. Microstructural evolution of a deformation zone in the upper ocean crust: evidence from DSDP Hole 504B. J. Geodyn., 13:119140 .

Alexander, R.J., Harper, G.D., and Bowman, J.R., 1992. Oceanic faulting and fault-controlled subseafloor hydrothermal alteration in the sheeted dike complex of the Josephine ophiolite. J. Geophys. Res., 98:97319760 .

Antonellini, M.A., and Cambray, F.W., 1992. Relations between sill intrusions and bedding-parallel extensional shear zones in the Mid-continent Rift System of the Lake Superior region. Tectonophysics, 212:331-349. 
Bailey, F.E., and Hirsch, P.B., 1962. The recrystallization process in some polycrystalline metals. Proc. R. Soc. London A, 267:11-30.

Beach, A., 1976. The interrelationships of fluid transport, deformation, geochemistry and heat flow in early Proterozoic shear zones in the Lewisian complex. Philos. Trans. R. Soc. London A, 280:569-604.

1980. Retrogressive metamorphic processes in shear zones with special reference to the Lewisian complex. J. Struct. Geol., 2:257-263.

Becker, K., 1989. Measurements of the permeability of the sheeted dikes in Hole 504B, ODP Leg 111. In Becker, K., Sakai, H., et al., Proc. ODP, Sci. Results, 111: College Station, TX (Ocean Drilling Program), 317-325.

Benn, K., and Allard, B., 1989. Preferred mineral orientations related to magmatic flow in ophiolite layered gabbros. J. Petrol., 30:925-946.

Berthé, D., Choukrome, P., and Jegouzo, P., 1979. Orthogneiss, mylonite and non-coaxial deformation and granites: the examples of South American shear zone. J. Struct. Geol., 1:31-42.

Bloomer, S.H., Meyer, P.S., Dick, H.J.B., Ozawa, K., and Natland, J.H., 1991. Textural and mineralogic variations in gabbroic rocks from Hole 735B. In Von Herzen, R.P., Robinson, P.T., et al., Proc. ODP, Sci. Results, 118: College Station, TX (Ocean Drilling Program), 21-39.

Borges, F.S., and White, S.H., 1980. Microstructural and chemical studies of sheared anorthosites, Roneval, South Harris. J. Struct. Geol., 2:273-280.

Bowen, N.L., 1920. Deformation of crystallizing magma. J. Geol., 26:265268.

Brown, W.L., Macaudière, D., and Ohnenstetter, M., 1980. Ductile shear zones in a meta-anorthosite from Harris, Scotland: textural and compositional changes in plagioclase. J. Struct Geol., 2:281-287.

Cambray, F.W., Vogel, T.A., and Mills, J.G., Jr., 1995. Origin of compositional heterogeneities in tuffs of the Timber Mountain Group: the relationship between magma batches and magma transfer and emplacement in an extensional environment. J. Geophys. Res., 100:15793-15805.

Cannat, M., Karson, J.A., Miller, D.J., et al., 1995. Proc. ODP, Init. Repts., 153: College Station, TX (Ocean Drilling Program).

Cooper, R.F., and Kohlstedt, D.L., 1986. Rheology and structure of olivinebasalt partial melts. J. Geophys. Res., 91:9315-9323.

Dell'Angelo, L.N., and Tullis, J., 1988. Experimental deformation of partially melted granitic aggregates. J. Metamorph. Geol., 6:495-515.

Detrick, R., Honnorez, J., Bryan, W.B., Juteau, T., et al., 1988. Proc. ODP, Init. Repts., 106/109: College Station, TX (Ocean Drilling Program).

Dick, H.J.B., Thompson, G., and Bryan, W.B., 1981. Low angle faulting and steady state emplacement of plutonic rocks at ridge-transform intersections. Eos, 62:406.

Hibbard, M.J., 1987. Deformation of incompletely crystallized magma systems: granitic gneisses and their tectonic implications. J. Geol., 95:543561 .

Hollister, L.S., and Crawford, M.L., 1986. Melt-enhanced deformation: a major tectonic process. Geology, 14:558-561.

Irvine, T.N., 1981. Terminology for layered intrusions. J. Petrol., 23:127162.

Ji, S., and Mainprice, D., 1988. Natural deformation fabrics of plagioclase: implications for slip systems and seismic anisotropy. Tectonophysics, 147:145-163.

1990. Recrystallization and fabric development in plagioclase. $J$. Geol., 98:65-79.

Ji, S., Mainprice, D., and Boudier, F., 1988. Sense of shear in high-temperature movement zones from the fabric asymmetry of plagioclase feldspars. J. Struct. Geol., 10:73-81.

Karson, J.A., and Dick, H.J.B., 1983. Tectonics of ridge-transform intersections at the Kane Fracture Zone, Mid-Atlantic Ridge. Mar. Geophys. Res., 6:51-98.

Karson, J.A., Thompson, G., Humphris, S.E., Edmond, J.M., Bryan, W.B., Brown, J.R., Winters, A.T., Pockalny, R.A., Casey, J.F., Campbell, A.C., Klinkhammer, G., Palmer, M.R., Kinzler, R.J., and Sulanowska, M.M., 1987. Along-axis variations in seafloor spreading in the MARK area. Nature, 328:681-685.

Karson, J.A., and Winters, A.T., 1992. Along-axis variations in tectonic extension and accommodation zones in the MARK area, Mid-Atlantic Ridge $23^{\circ} \mathrm{N}$ latitude: ophiolites and their modern oceanic analogues. In Parson, L.M., Murton, B.J., and Browning, P. (Eds.), Geol. Soc. Spec. Publ. London, 60:107-116.

Kerrich, R., 1986. Fluid infiltration into fault zones: chemical, isotopic, and mechanical effect. Pure Appl. Geophys., 124:225-268.

Kerrich, R., Kamineni, D.C., Borre, D., Baldwin, D.K., McLarty, E., and Thivierge, R.H., 1987. Cyclic deformation and chemical transport in the Folson Lake fault zone, East Bull Lake anorthosite-gabbro complex: evidence for seismic pumping? Appl. Geochem., 2:103-126.
Kronenberg, A.K., and Shelton, G.L., 1980. Deformation microstructures in experimentally deformed Maryland diabase. J. Struct. Geol., 2:341-353.

Kruhl, J.H., 1987. Preferred lattice orientations of plagioclase from amphibolite and greenschist facies rocks near the Insubric line (Western Alps). Tectonophysics, 135:233-242.

Liou, J.G., Kuniyoshi, S., and Ito, K., 1974. Experimental studies of the phase relations between greenschist and amphibolite in a basaltic system. Am. J. Sci., 274:613-632.

Lister, G.S., and Snoke, A.W., 1984. S-C mylonites. J. Struct. Geol., 6:617638.

McCaig, A.M., 1984. Fluid-rock interaction in some shear zones from the Pyrenees. J. Metamorph. Geol., 2:129-141.

Means, W.D., and Park, Y., 1994. New experimental approach to understanding igneous texture. Geology, 22:323-326.

Mercier, J.-C., 1986. Olivine and pyroxenes. In Wenk, H.-R. (Ed.), Preferred Orientation in Deformed Metals and Rocks: An Introduction to Modern Texture Analysis: London (Acad. Press), 407-430.

Mével, C., Cannat, M., Gente, P., Marion, E., Auzende, J.-M., and Karson, J.A., 1991. Emplacement of deep crustal and mantle rocks on the west median valley wall of the MARK area (MAR $23^{\circ} \mathrm{N}$ ). Tectonophysics, 190:31-53.

Oleson, N.O., 1987. Plagioclase fabric development in a high-grade shear zone, Jotunheimen, Norway. Tectonophysics, 142:291-308.

Olsen, T.S., and Kohlstedt, D.L., 1985. Natural deformation and recrystallization of some intermediate plagioclase feldspars. Tectonophysics, 111:107-131.

Paquet, J., and Francois, P., 1980. Experimental deformation of partially melted granitic rocks at $600^{\circ}-900^{\circ} \mathrm{C}$ and $250 \mathrm{MPa}$ confining pressure. Tectonophysics, 68:131-146.

Potdevin, J.L., Lardeaux, J.M., and Coffrant, D., 1989. Mass transfer related to ductile shear zone development in a metagabbro. In Bridgewater, D. (Ed.), Fluid Movements-Element Transport and Composition of the Deep Crus: Dordrecht (Kluwer), 213-230.

Prior, D.J., Knipe, R.J., and Handy, M.R., 1990. Estimates of the rates of microstructural change in mylonites. In Knipe, R.J., and Rutter, E.H. (Eds.), Deformation Mechanisms, Rheology and Tectonics. Geol. Soc. Spec. Publ. London, 54:309-320.

Pryer, L.L., 1993. Microstructures of feldspars from a major crustal thrust zone: the Grenville Front, Ontario, Canada. J. Struct. Geol., 15:21-36.

Purdy, G.M., and Detrick, R.S., 1986. Crustal structure of the Mid-Atlantic Ridge at $23^{\circ} \mathrm{N}$ from seismic refraction studies. J. Geophys. Res., 91:3739-3762

RIDGE Workshop Proceedings, 1995. The interaction of magmatism and faulting. Lake Tahoe.

Robinson, P.T., Von Herzen, R., et al., 1989. Proc. ODP, Init. Repts., 118: College Station, TX (Ocean Drilling Program).

Rutherford, E., 1993. Structural and metamorphic evolution of ophiolites and oceanic crust, illustrated by hydrothermal alteration profiles in DSDP Hole 504B, the Troodos Ophiolite and the Bay of Islands Ophiolite [Ph.D. dissert.]. Univ. of Houston.

Rutter, E.H., and Neumann, D., 1995. Experimental deformation of partially molten Westerly Granite under fluid-absent conditions, with implications for the extraction of granite magmas. J. Geophys. Res., 100:15,69715,715 .

Schulz, N.J., Detrick, R.S., and Miller, S.P., 1988. Two- and three-dimensional inversions of magnetic anomalies in the MARK area (Mid-Atlantic Ridge, $23^{\circ}$ N). Mar. Geophys. Res., 10:41-57.

Shipboard Scientific Party, 1995a. Explanatory Notes. In Cannat, M., Karson, J., Miller, J. et al., Proc. ODP Sci Results, 153: College Station, TX (Ocean Drilling Program), 15-42.

1995b. Introduction. In Cannat, M., Karson, J., Miller, J. et al., Proc. ODP Sci Results, 153: College Station, TX (Ocean Drilling Program), 5-13.

Spear, F.S., 1981. An experimental study of hornblende stability and compositional variability in amphibolite. Am. J. Sci., 281:697-734.

Tullis, J., 1983. Deformation of feldspars. In Ribbe, P.H. (Ed.), Feldspar Mineralogy. Rev. Mineral., 2:297-323.

Tullis, J., and Yund, R.A., 1987. Transition from cataclastic flow to dislocation creep of feldspar: mechanisms and microstructures. Geology, 15:606-609.

Twiss, R.J., 1977. Theory and applicability of a recrystallized grain size paleopiezometer. Pure Appl. Geophys., 115:227-244.

1986. Variable sensitivity piezometric equations for dislocation density and subgrain diameter and their relevance to olivine and quartz. In Hobbs, B.E., and Heard, H.C. (Eds.), Mineral and Rock Deformation: 
Laboratory Studies. Am. Geophys. Union, Geophys. Monogr., 36:247261.

Underwood, E.E., 1970. Quantitative Stereology: Reading, MA (AddisonWesley).

Urai, J.L., Means, W.D., Lister, G.S., 1986. Dynamic recrystallization of minerals. In Hobbs, B.E., and Heard, H.C. (Eds.), Mineral and Rock Deformation: Laboratory Studies. Am. Geophys. Union, Geophys. Monogr., 36:161-200.

Van der Molen, I., and Paterson, M.S., 1979. Experimental deformation of partially-melted granite. Contrib. Mineral. Petrol., 70:299-318.

Wenk, H.R., Bunge, H.J., Jansen, E., and Pannetier, J., 1986. Preferred orientation of plagioclase-neutron diffraction and U-stage data. Tectonophysics, 126:271-284.

White, J.C., 1990. Albite deformation within a basal ophiolite shear zone. In Knipe, R.J., and Rutter, E.H., (Eds.), Deformation Mechanisms, Rheology and Tectonics. Geol. Soc. Spec. Publ. London, 54:327-333.

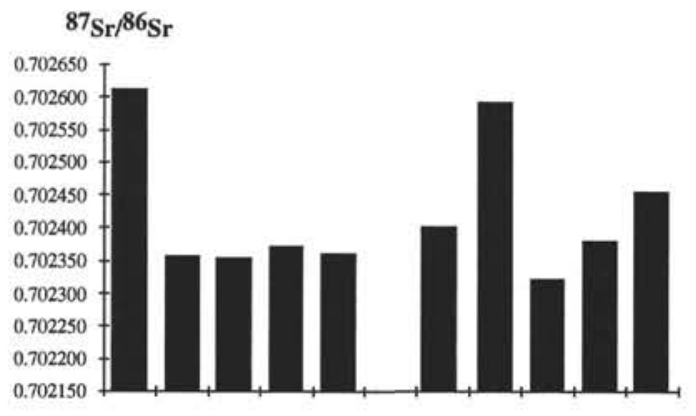

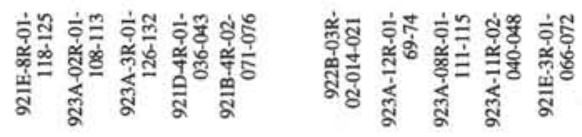
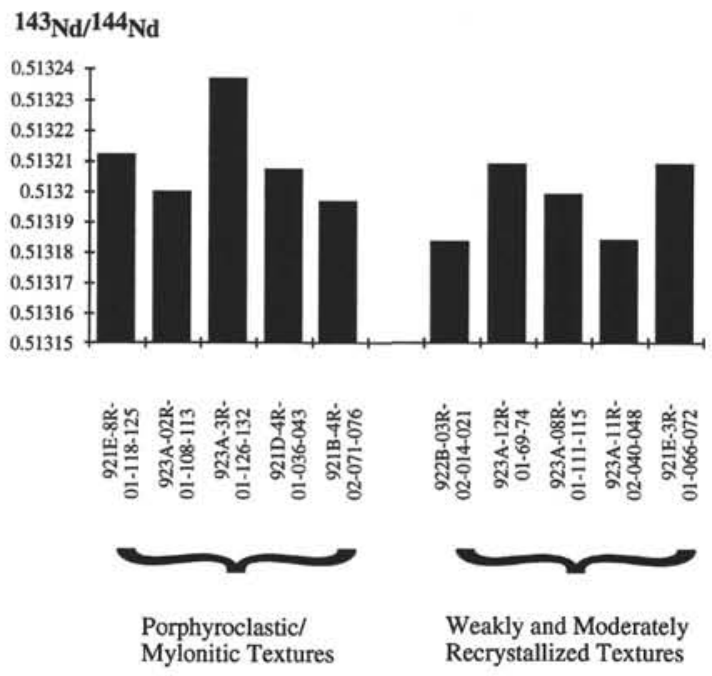

White, S.H., 1976. Tectonic deformation and recrystallization of oligoclase. Contrib. Mineral. Petrol., 50:287-304.

Yund, R.A., and Tullis, J., 1991. Compositional changes of minerals associated with dynamic recrystallization. Contrib. Mineral. Petrol., 108:346355.

Zhao, S., Jr., and Zhao, P., 1994. On the measurement of plagioclase lattice preferred orientations. J. Struct. Geol., 16:1711-1718.

Date of initial receipt: 2 August 1995

Date of acceptance: 22 February 1996

Ms 153SR-007
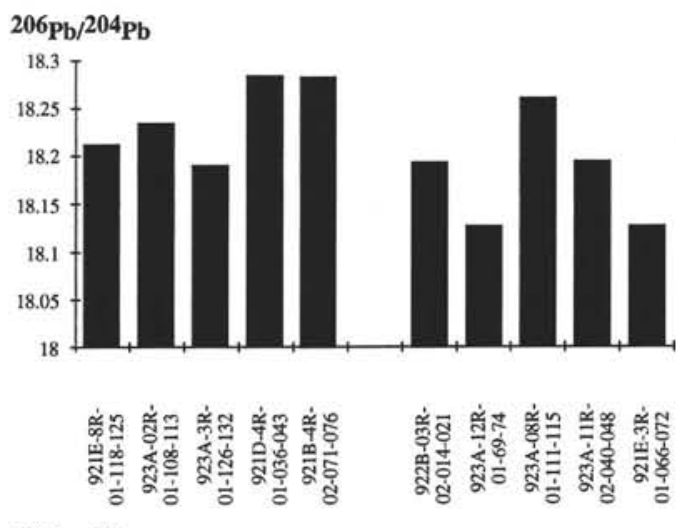

${ }^{207} \mathrm{~Pb} / 204 \mathrm{~Pb}$
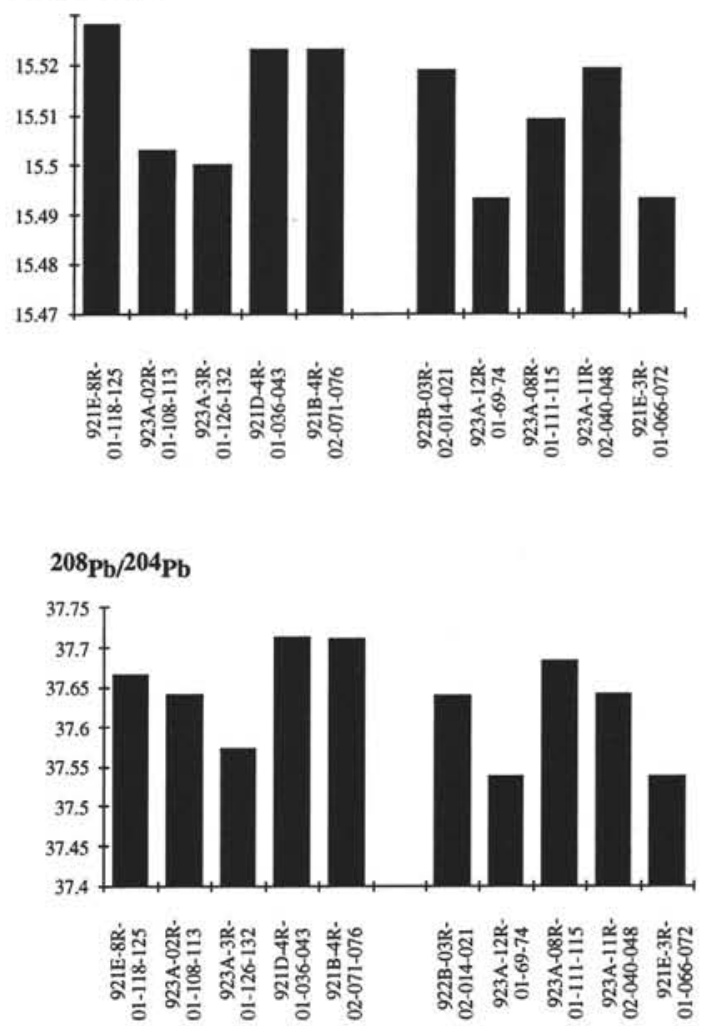

Figure 11. Plots of ${ }^{87} \mathrm{Sr} /{ }^{86} \mathrm{Sr},{ }^{143} \mathrm{Nd} /{ }^{144} \mathrm{Nd},{ }^{206} \mathrm{~Pb} /{ }^{204} \mathrm{~Pb},{ }^{207} \mathrm{~Pb} /{ }^{204} \mathrm{~Pb}$, and ${ }^{208} \mathrm{~Pb} /{ }^{204} \mathrm{~Pb}$. Data are from Table 4. Samples in the left group are porphyroclastic and mylonitic. Samples in the right group are weakly and moderately recrystallized. 

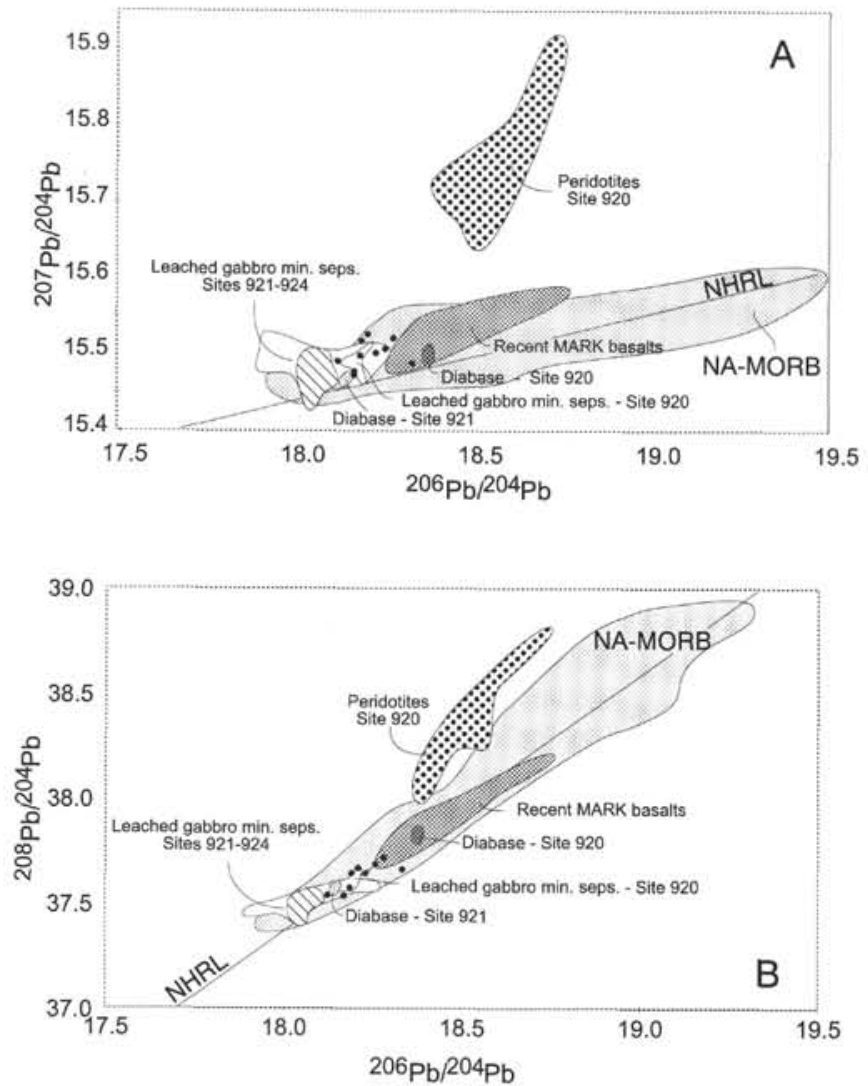

Figure 12. Plots of ${ }^{206} \mathrm{~Pb} /{ }^{204} \mathrm{~Pb}$ vs. (A) ${ }^{207} \mathrm{~Pb} /{ }^{204} \mathrm{~Pb}$ and $(\mathbf{B}){ }^{208} \mathrm{~Pb} /{ }^{204} \mathrm{~Pb}$. Data plotted are average compositions from Table 4 . Whole-rock gabbros from Site 921 to 924 are shown as solid circles. Shown for comparison is the field (unshaded) for leached gabbro mineral separates from Sites 920 to 924 (Kempton and Hunter, this volume); the diagonally striped field is the more restricted range for samples from Sites 921 to 924 , which exhibit isotopic equilibrium between coexisting plagioclase and pyroxene. Other data shown include peridotites from Site 920 (Kempton and Hunter, this volume), diabase dikes from Sites 920 and 921 (Kempton and Casey, this volume). Data sources for the fields of recent MARK basalt glasses and North Atlantic NMORB (NA-MORB) are as listed in Kempton and Hunter (this volume).
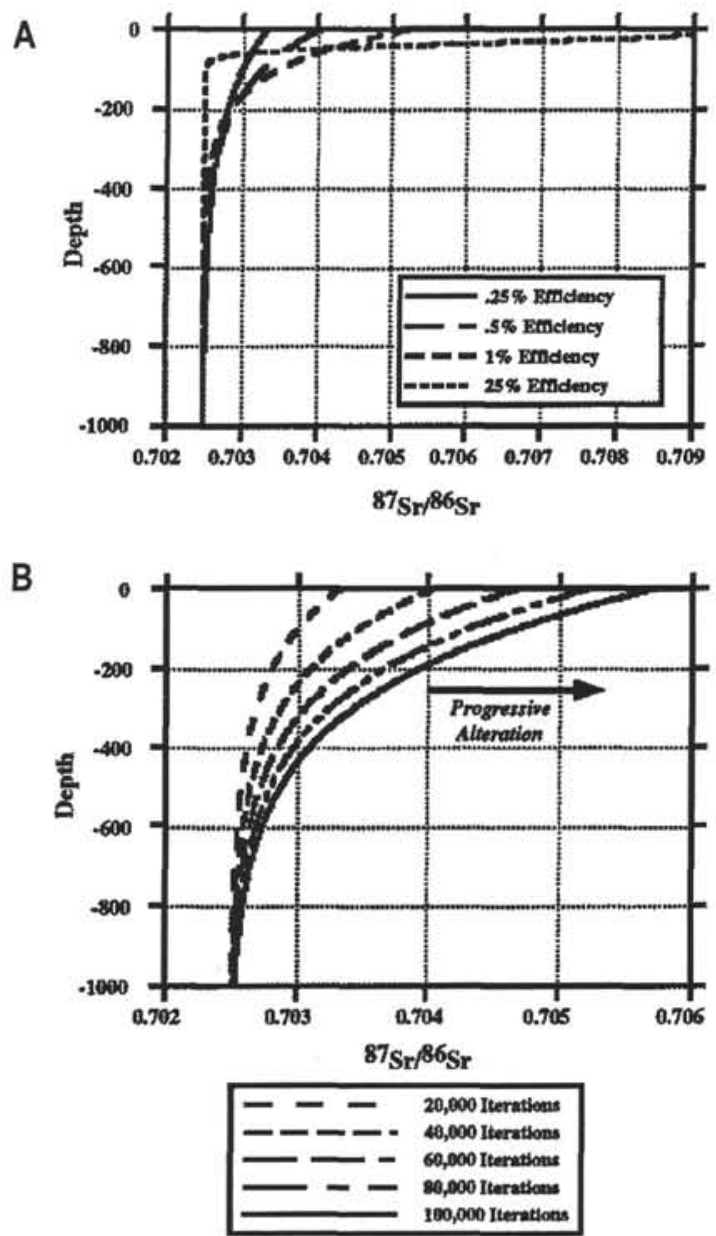

Figure 13. Effects of the exchange efficiency factor on the shape of ${ }^{87} \mathrm{Sr} /{ }^{86} \mathrm{Sr}$ alteration profiles. A. Alteration in the modeling takes place by repeated invasions of a column of mafic rock by pristine seawater. As the water migrates through the column, it alters the host rock and is itself altered. High uniform efficiencies result in extensive $\mathrm{Sr}$-isotopic abundances in the uppermost part of the crustal column, but leave the lower level rocks unaltered. Low efficiencies allow fluids capable of contributing significant ${ }^{87} \mathrm{Sr}$ to the rocks to reach greater depths. Efficiencies of 0.25 generally correlate with Hole 504B isotope data (Rutherford, 1993). B. Synthetic curves resulting from the interaction of seawater $\left(\mathrm{Sr}=8 \mathrm{ppm},{ }^{87} \mathrm{Sr} /{ }^{86} \mathrm{Sr}=0.7092\right)$, with a rock column of uniform composition $\left(\mathrm{Sr}=120 \mathrm{ppm},{ }^{87} \mathrm{Sr} /{ }^{86} \mathrm{Sr}=0.7024\right)$ using a smoothly decaying porosity curve (after Becker, 1989, for Hole 504B). The curves are shown at 20,000 iterations of seawater recharge increments, and show the changes in the form of the alteration profile through progressive alteration. Hole $504 \mathrm{~B}$, in young crust, fits ${ }^{87} \mathrm{Sr} /{ }^{86} \mathrm{Sr}$ profiles less than 20,000 . The MARK region would therefore show little alteration at depths of more than about $400 \mathrm{~m}$. 
1
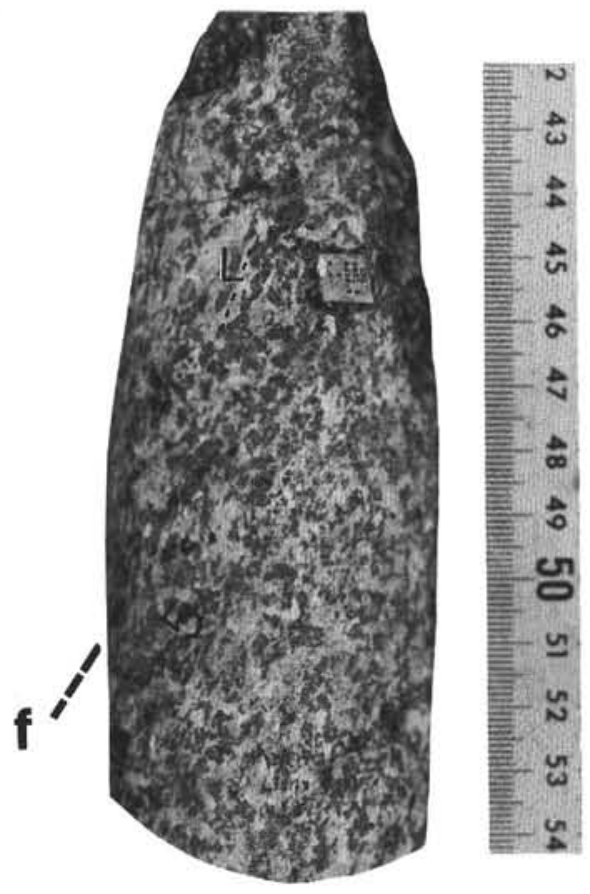

2

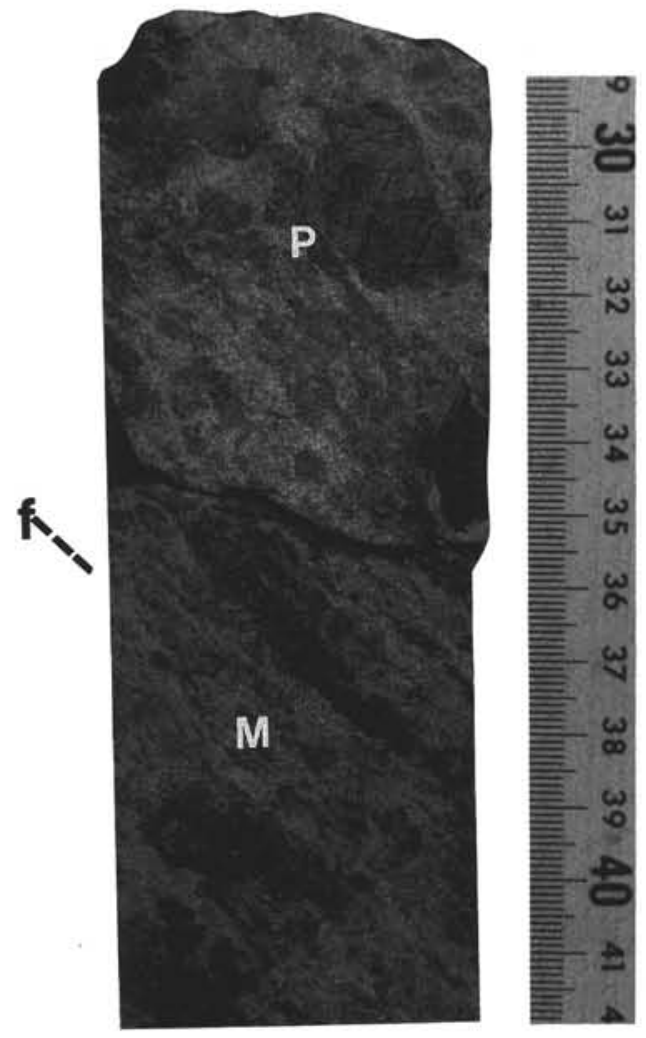

3

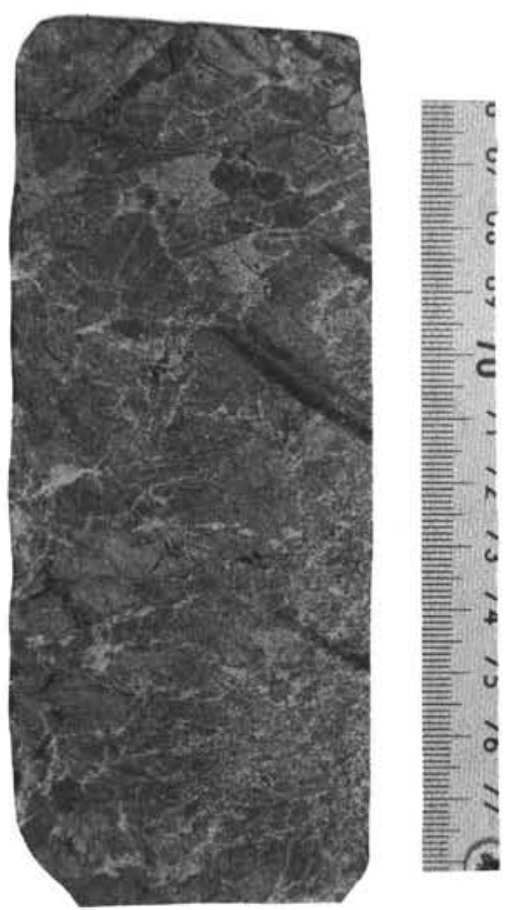

4

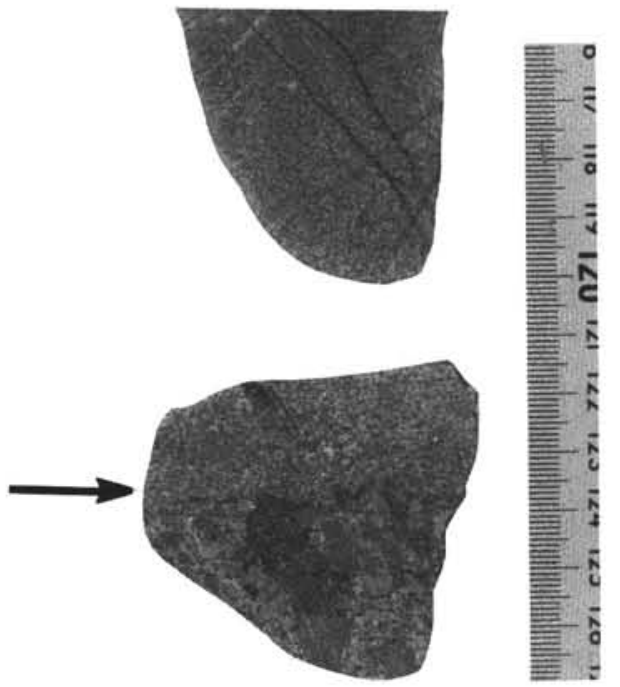

Plate 1. Examples of core sample deformation fabrics. Scale bar shows $\mathrm{cm}$ and $\mathrm{mm}$ divisions for sample interval. 1. A shape-preferred orientation of clinopyroxene defines the steeply dipping foliation (approximate orientation shown by dashed line (f), and a weak lineation (dashed line, L). Sample 153-921 B-3R-2, 40$54 \mathrm{~cm}$ (porphyroclastic texture). 2. Core sample showing gradational decrease in grain size and increasing definition of foliation (dashed line, $\mathrm{f}$, shows orientation of foliation) from the porphyroclastic texture (upper half, P) into the mylonitic texture (lower half, M). Sample 153-923A-3R-2, 30-40 cm. 3. Meshwork of dynamically recrystallized plagioclase (white veinlets) surrounding weakly deformed clinopyroxene crystals in a pegmatitic gabbro where the primary cumulus texture is still evident. Sample 153-923A-13R-3, 63-80 cm (not among samples used in this study). 4. Sharp contact (arrow) between a fine-grained, mylonitized gabbro and porphyroclastic texture. Sample 153-923A-16R-3, 118-125 cm. 

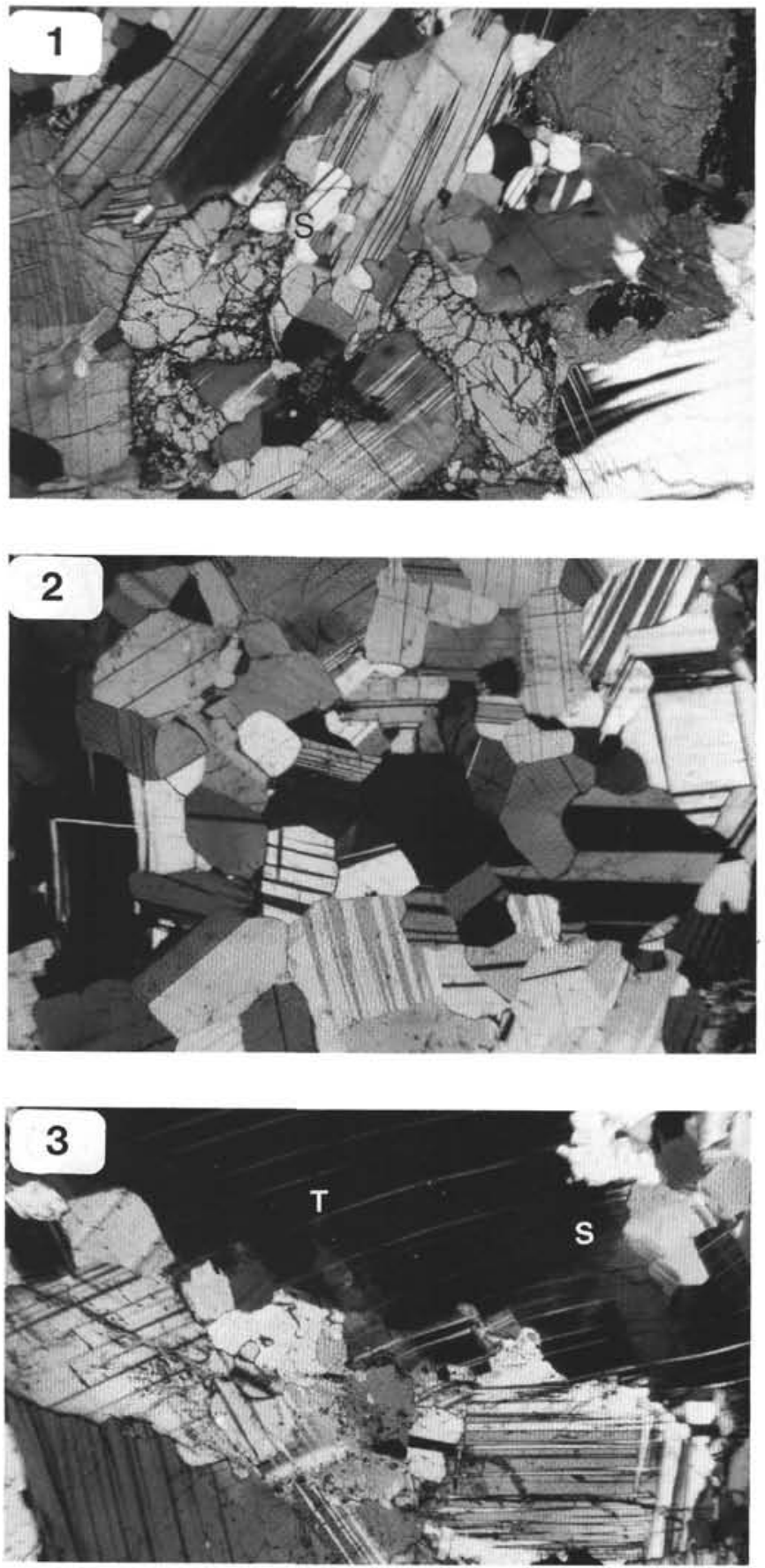
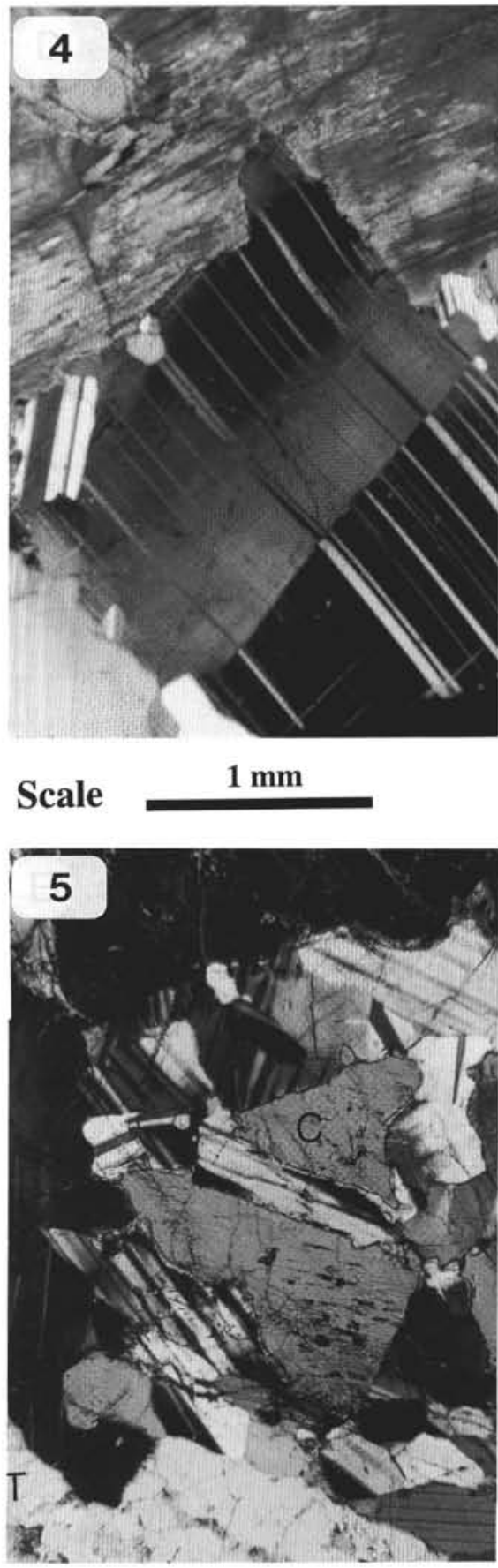

Plate 2. Examples of microstructures in weakly and moderately recrystallized textures (crossed polarized light). 1. Weakly recrystallized plagioclase and olivine. Rotation recrystallization is evident in plagioclase where subgrains rotate deformation twins (s). Recrystallized plagioclase grain boundaries commonly meet at $120^{\circ}$ triple points. Neoblast boundaries are generally smooth and gently curved. The igneous morphologies of olivine grains are still evident, but some polygonization occurs on the grain extremities. Sample 153-921D-5R-2, 68-73 cm. 2. Plagioclase neoblasts in a weakly recrystallized gabbro. Albite and perthite deformation twins tend to be more abundant in the moderately recrystallized texture, but the neoblast characteristics are otherwise similar. Sample 153$923 \mathrm{~A}-8 \mathrm{R}-2,13-19 \mathrm{~cm}$. 3. Relict plagioclase grain in moderately recrystallized texture displaying complex substructure. The margin of the relict grain is highly irregular. Deformation twins ( $\mathrm{T}$ ) within the grain are deformed by bending of the crystal lattice as indicated by the patchy undulose extinction. Subgrain (S) formation rotates the deformation twins by less than $5^{\circ}$. Some of the recrystallized grains have small, isolated protrusions at their margins, suggesting that limited grain boundary migration occurred. Sample 153-923A-3R-1, 100-105 cm. 4. Kink band in relict plagioclase grain in weakly recrystallized texture. Albite deformation twins are deformed by the sharp boundaries of a 0.5-mm-wide kink band. Sample 153-923A-8R-2, 81-88 cm. 5. Undeformed clinopyroxene oikocryst containing plagioclase inclusion. The dismemberment of clinopyroxene $(C)$ oikocrysts can be traced from their primary igneous textures to partial disruption (as in this example) and to complete separation where the plagioclase matrix and inclusions are indistinguishable and dismembered clinopyroxene crystals with characteristically straight edges are suspended in the plagioclase matrix. This process gives many samples a brecciated appearance, although the separation of clinopyroxene fragments may be a dominantly crystal-plastic process. Sample $153-922 \mathrm{~A}-2 \mathrm{R}-5,68-73 \mathrm{~cm}$. 

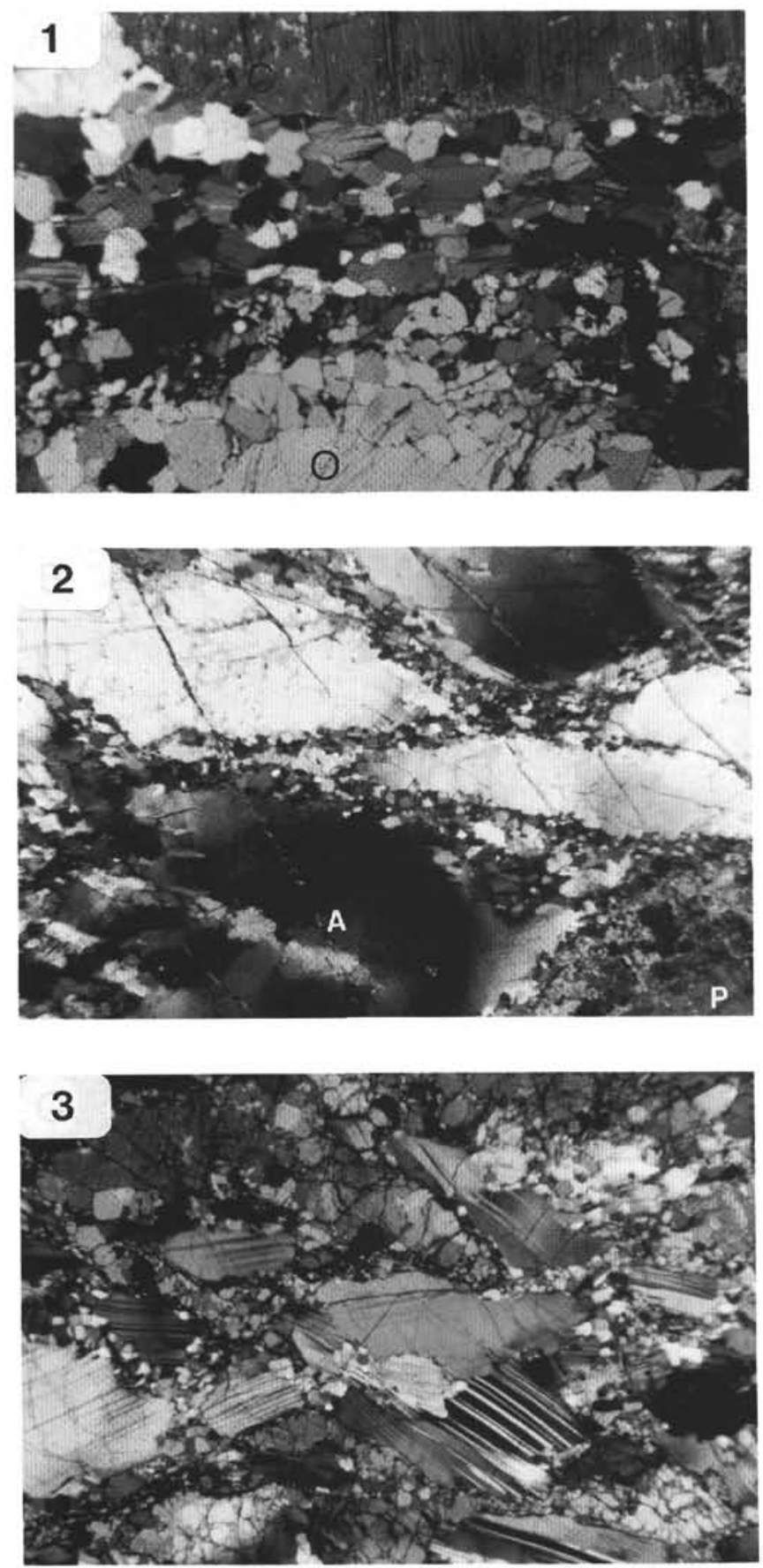
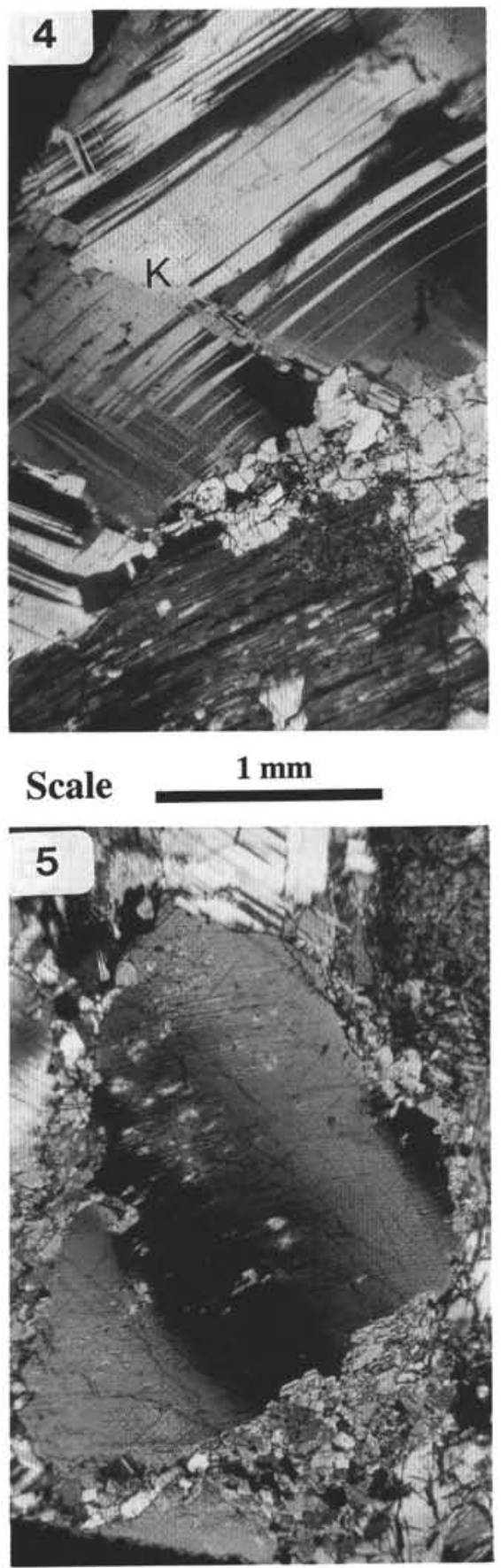

Plate 3. Examples of microstructures in the porphyroclastic texture (cross-polarized light). 1. Recrystallized plagioclase matrix, core and mantle structure in olivine and undeformed clinopyroxene. Deformation twins in plagioclase neoblasts tend to be aligned parallel to the foliation (horizontal). Neoblast boundaries have varied morphologies ranging from gently curved to weakly serrated. The olivine porphyroclast $(\mathrm{O})$ (lower part of image) is mantled by polygonal recrystallized olivine. An undeformed clinopyroxene (C) grain containing exsolution lamellae is located in the upper part of the image. Sample 153-923A-3R-2, 47$51 \mathrm{~cm}$. 2. Plagioclase "ribbon" grains in porphyroclastic texture. Plagioclase porphyroclasts have a shape-preferred orientation subparallel to the foliation and display a complex substructure. Plagioclase neoblasts form interconnected, anastomosing stringers that are subparallel to the foliation. The recrystallized margin of a pyroxene grain is shown in the lower right of the image (P). Alteration of brown and green amphibole alteration is concentrated in the recrystallized rim. Veins of brown and green amphibole (A) postdate the crystal-plastic deformation. Sample 153-922A-2R-1, 85-87 cm. 3. Strongly twinned plagioclase porphyroclasts with recrystallized olivine. In the porphyroclastic texture, olivine is more extensively recrystallized and olivine neoblasts (polygonal grains) are distributed subparallel to the foliation, forming an anastomosing "meshwork" with recrystallized plagioclase. Sample 153-922A-2R-1, 85-87 cm. 4. Recrystallization along narrow kink bands in a plagioclase porphyroclast. The boundaries of the center kink band $(\mathrm{K})$ have become weakly serrated where recrystallization by strain-induced grain boundary migration has occurred. The kink band deforms albite deformation twins. Sample 153-922B-2R-2, 73-77 cm. 5. Kink bands in clinopyroxene porphyroclast. The deflection of exsolution lamellae and the banded undulatory extinction delineate a kink band ( $0.5 \mathrm{~mm}$ wide). The porphyroclast has a weakly serrated margin and is partly enclosed by pyroxene neoblasts. Brown amphibole alteration is focused in the recrystallized margin. Sample $153-921 \mathrm{~B}-4 \mathrm{R}-2,71-76 \mathrm{~cm}$. 

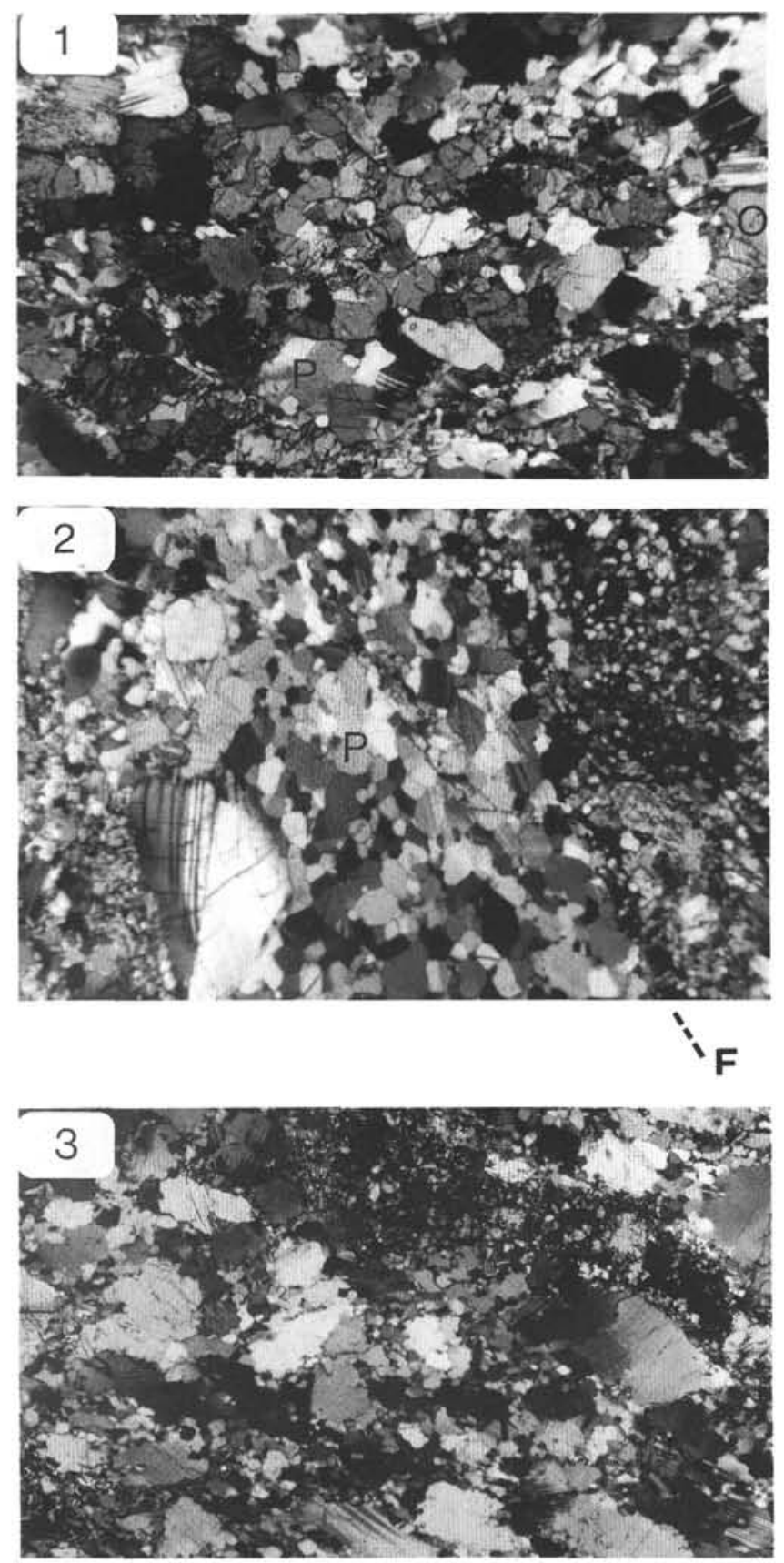
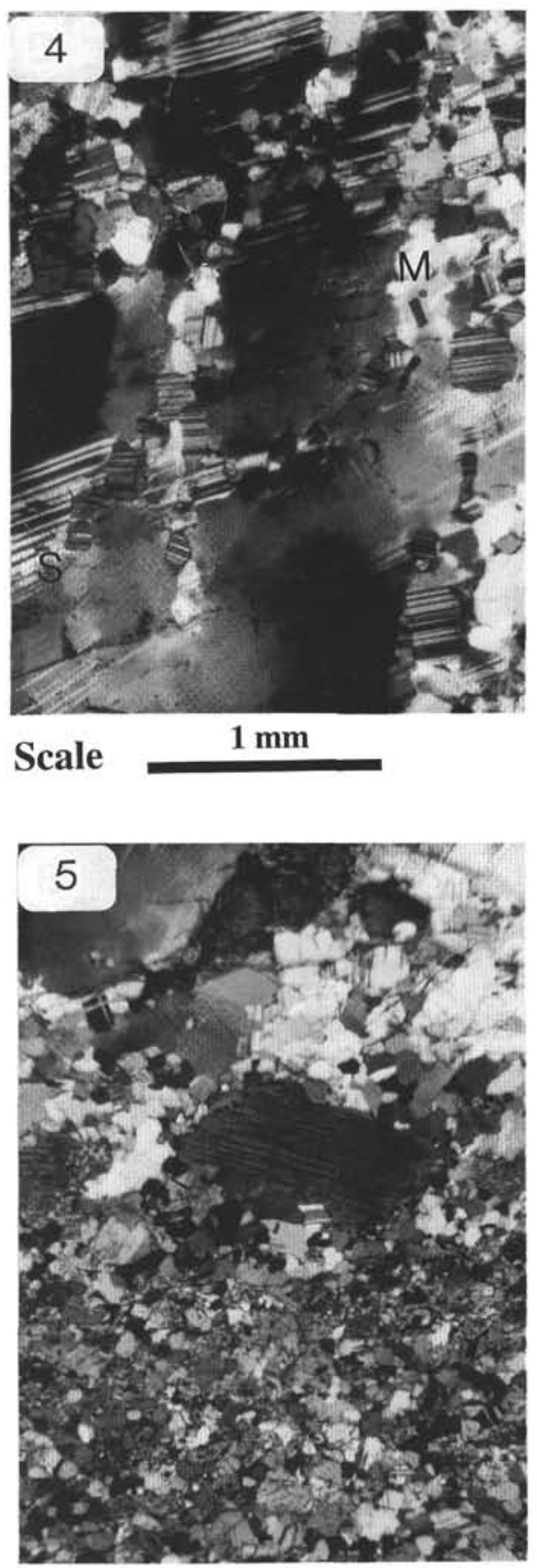

Plate 4. Examples of mylonitic textures (cross-polarized light). 1. Recrystallized plagioclase $(\mathrm{P})$ and olivine $(\mathrm{O})$ illustrating the more even dispersion of grain size and phases in the mylonitic texture. Sample 153-923A-15R-1, 117-122 cm. 2. Grain-size gradient associated with modal composition variations in a mylonitic shear zone. As in the porphyroclastic texture, albite deformation twins tend to be aligned subparallel to the foliation (top left to bottom right, F). The recrystallized grain size decreases markedly from a plagioclase-rich band $(\mathrm{P})$ to a band whose composition is dominantly clinopyroxene and Fe-Ti oxides (righthand side). The compositional banding is oriented parallel to the foliation. Sample 153-922A-2R-1, 83-87 cm. 3. Recrystallized plagioclase grains with highly serrated grain boundaries. This texture contrasts with other mylonitic textures that have more polygonal neoblasts with gently curved or weakly lobate boundaries. In this example, both neoblasts and porphyroclasts have highly serrated margins attributed to strain-induced grain boundary migration. Sample 153-921E3R-1, 41-44 cm. 4. Recrystallization of plagioclase porphyroclast in a mylonitic gabbro. In the mylonitic texture, recrystallization by subgrain formation (S) and grain boundary migration $(\mathrm{M})$ occurs throughout porphyroclasts. In the porphyroclastic texture, recrystallization tends to be concentrated around the margins of the grains. Sample 153-921E-8R-1, 78-80 cm. 5. Sharp grain-size gradient at the boundary of a mylonitic shear zone. The lower half of the image shows fine-grained plagioclase and clinopyroxene. The recrystallized clinopyroxene is partly altered by brown amphibole. The mylonite has a weak foliation ( $\mathrm{F}$, barely evident at the scale of this image) defined by a shape-preferred orientation of clinopyroxene. A crystallographic-preferred orientation of recrystallized plagioclase grains parallel to the foliation is also evident upon insertion of a gypsum plate. The upper half of the image contains a weakly to moderately recrystallized gabbro. The transition between the two textures is less than $2 \mathrm{~mm}$ thick. Sample 153-923A-16R-3, 118-124 cm. 


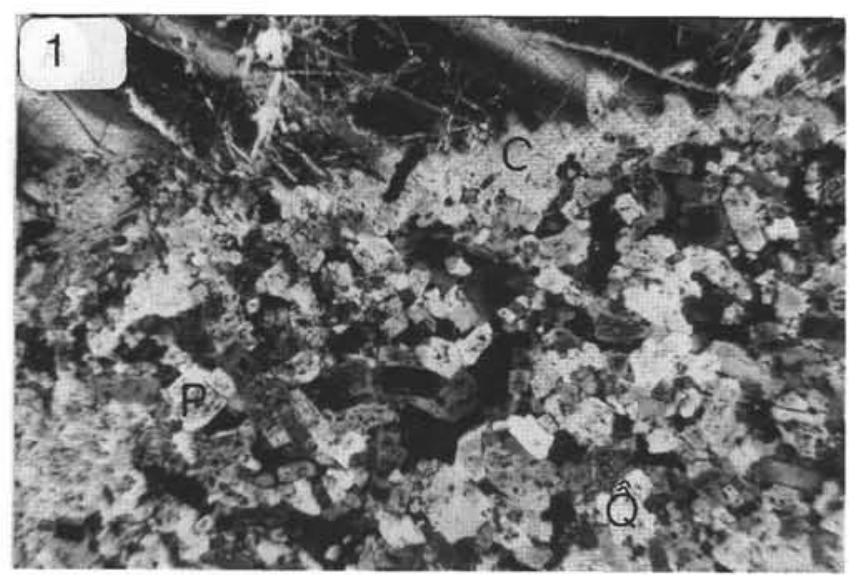

Scale
$1 \mathrm{~mm}$

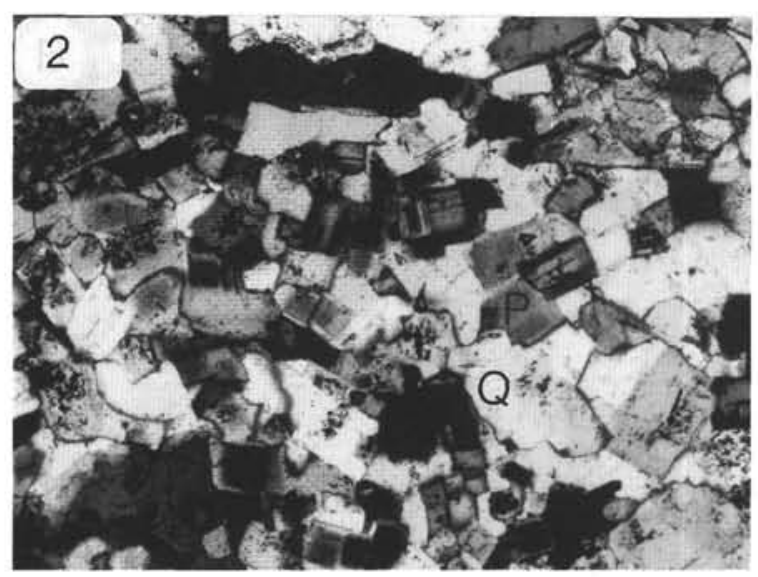

Scale

\section{$250 \mu \mathrm{m}$}

Plate 5. Microstructures in a leucocratic vein associated with a gabbroic shear zone (Sample 153-921E-8R-1, 91-95 cm; cross-polarized light). 1. Contact between leucocratic vein and wallrock plagioclase. Broad twins in the plagioclase grain are obliterated at the margin by a diffuse contact zone (pale region, $\mathrm{C}$ ) that has a serrated margin. Plagioclase grains $(\mathrm{P})$ within the vein are euhedral and fairly equant, whereas the quartz grains $(\mathrm{Q})$ have more irregular grain boundaries. 2. Detail of compositional zoning and albite twins in the cores of plagioclase grains. Twinning generally occurs only in the center of grains. Quartz with lobate grain boundaries surrounds the plagioclase crystals. 